\title{
Effect of yeast and essential oil-enriched diets on critical determinants of health and immune function in Africanized Apis mellifera
}

\author{
César Canché Collí ${ }^{1}$, Humberto José Estrella Maldonado ${ }^{1}$, Luis A. Medina-Medina ${ }^{2}$, Humberto Moo Valle ${ }^{2}$, Luz \\ Maria Calvo-Irabien ${ }^{1}$, Elisa Chan-Vivas ${ }^{1},{\text { Rosalina } \operatorname{Rodríguez}^{1} \text {, Azucena Canto }}^{\text {Corresp. } 1}$ \\ 1 Unidad de Recursos Naturales, Centro de Investigacion Cientifica de Yucatan, A.C., Merida, Yucatan, Mexico \\ Departamento de Apicultura, Campus de Ciencias Biologicas y Agropecuarias, Universidad Autonoma de Yucatan, Merida, Yucatan, Mexico \\ Corresponding Author: Azucena Canto \\ Email address: azucanto@cicy.mx
}

Nutrition is vital for health and immune function in honey bees (Apis mellifera). The effect of diets enriched with bee-associated yeasts and essential oils of Mexican oregano (Lippia graveolens) was tested on survival, food intake, accumulated fat body tissue, and gene expression of vitellogenin $(\mathrm{Vg})$, prophenoloxidase (proPO) and glucose oxidase (GOX) in newly emerged worker bees. The enriched diets were provided to bees under the premise that supplementation with yeasts or essential oils can enhance health variables and the expression of genes related to immune function in worker bees. Based on a standard pollen substitute, used as a control diet, enriched diets were formulated, five with added bee-associated yeasts (Starmerella bombicola, Starmerella etchellsii, Starmerella bombicola 2, Zygosaccharomyces mellis, and the brewers' yeast Saccharomyces cerevisiae) and three with added essential oils from L. graveolens (carvacrol, thymol, and sesquiterpenes). Groups of bees were fed one of the diets for 9 or 12 days. Survival probability was similar in the yeast and essential oils treatments in relation to the control, but median survival was lower in the carvacrol and sesquiterpenes treatments. Food intake was higher in all the yeast treatments than in the control. Fat body percentage in individual bees was slightly lower in all treatments than in the control, with significant decreases in the thymol and carvacrol treatments. Expression of the genes $\mathrm{Vg}$, proPO, and GOx was minimally affected by the yeast treatments but was adversely affected by the carvacrol and thymol treatments. 


\section{Effect of yeast and essential oil-enriched diets on}

\section{4 critical determinants of health and immune function in}

\section{Africanized Apis mellifera}

7 César Canché-Collí ${ }^{1}$, Humberto Estrella-Maldonado ${ }^{1}$, Luis A. Medina-Medina ${ }^{2}$, Humberto Moo-

8 Valle $^{2}$, Luz María Calvo-Irabien ${ }^{1}$, Elisa Chan-Vivas ${ }^{1}$, Rosalina Rodríguez ${ }^{1}$, Azucena Canto*1

${ }^{1}$ Centro de Investigacion Cientifica de Yucatan A.C. (CICY) Calle 43 No. 130, Colonia

Chuburna de Hidalgo, 97205 Merida, Yucatan, Mexico. Phone number: (52) 9999428330 Ext

371

${ }^{2}$ Departamento de Apicultura, Campus de Ciencias Biologicas y Agropecuarias, Universidad Autonoma de Yucatan, Apartado Postal 4-116, 97100 Merida, Yucatan, México. Phone number:

*Corresponding Author:

Azucena Canto azucanto@cicy.mx

Centro de Investigacion Cientifica de Yucatan A.C. (CICY) Calle 43 No. 130, Colonia Chuburna de Hidalgo, 97205 Merida, Yucatan, Mexico. Cell phone number: (52) 9991539949 


\section{Abstract}

24 Nutrition is vital for health and immune function in honey bees (Apis mellifera). The effect of

diets enriched with bee-associated yeasts and essential oils of Mexican oregano (Lippia

graveolens) was tested on survival, food intake, accumulated fat body tissue, and gene

emerged worker bees. The enriched diets were provided to bees under the premise that supplementation with yeasts or essential oils can enhance health variables and the expression of genes related to immune function in worker bees. Based on a standard pollen substitute, used as a control diet, enriched diets were formulated, five with added bee-associated yeasts (Starmerella bombicola, Starmerella etchellsii, Starmerella bombicola 2, Zygosaccharomyces mellis, and the brewers' yeast Saccharomyces cerevisiae) and three with added essential oils from L. graveolens (carvacrol, thymol, and sesquiterpenes). Groups of bees were fed one of the diets for 9 or 12 days. Survival probability was similar in the yeast and essential oils treatments in relation to the control, but median survival was lower in the carvacrol and sesquiterpenes treatments. Food intake was higher in all the yeast treatments than in the control. Fat body percentage in individual bees was slightly lower in all treatments than in the control, with significant decreases in the thymol and carvacrol treatments. Expression of the genes $V g$, proPO, and $G O x$ was minimally affected by the yeast treatments but was adversely affected by the carvacrol and 41 thymol treatments.

42 Keywords: Honey bee, native plants, native bees, nutrition, immune system, bee-associated 43 yeasts, essential oils, pollen substitutes. 


\section{Introduction}

45 One way of improving the health of honey bee colonies is to provide diets containing compounds that strengthen their health and immune function. Beekeepers supply their honey bee colonies with pollen diets or pollen substitutes to strengthen them during critical feeding or illness periods. Research is needed to identify diet components that effectively strengthen honey bee health. Nutritional stress can increase insect susceptibility to diseases, pests, and pesticides (Di Pasquale et al., 2013; Goulson et al., 2015). Nutrition enhances critical determinants of health and immune function in several ways. For instance, dietary protein provides essential amino acids for synthesizing vitellogenin, phenoloxidase and glucose oxidase, and promotes the accumulation of fat body tissue (Alaux et al., 2010; Negri et al., 2019).

The gene $V g$ is involved in the production of vitellogenin. It is synthesized in insects' abdominal fat body and has longevity-enhancing, antioxidant and immunological functions in honey bees (Amdam et al., 2004). The proPO gene is involved in the production of phenoloxidase, a precursor (zymogen) of phenoloxidase, which triggers the melanization process, a humoral response to pathogens and parasites (González-Santoyo \& Córdoba-Aguilar, 2012). Glucose oxidase is critical to the inhibition of pathogens in bee food. It is produced in the hypopharyngeal glands of worker bees and secreted, through a channel that opens into the mouth onto the hypopharynx, into bee bread and honey (Ohashi, Natori \& Kubo, 1999). The amount of fat body tissue is a component in biosynthetic and metabolic activity in bees because it controls the synthesis and utilization of energy reserves and synthesizes most of the hemolymph proteins involved in insect defense against pathogens (Wilson-Rich, Dres \& Starks, 2008). Yeasts isolated from hive products (e.g., bee bread, larval food, and honey; Gilliam, 1979; Rosa et al., 2003) can modulate bee health and immune function. For example, the brewers' yeast 
67 Saccharomyces cerevisiae is widely used in honey bee feed as a source of proteins in periods of

68

69 nectar and pollen scarcity (Standifer et al., 1960). Although some research has been done on yeasts in bee nutrition, further studies are needed to understand how yeasts isolated from bee food sources modulate colony nutrition.

Essential oils (EOs) are also used as bee diet supplements. Honey bees actively collect several phytochemicals that are also dominant components in essential oils, and many of these compounds have antibiotic activity against pathogens and parasites (Erler \& Moritz, 2016). Honey bees fed plant-derived phytochemicals survive longer and have a high capacity to overcome infections (Bernklau et al., 2019). Essential oils or single compounds isolated from them such as camphor, carvacrol, eucalyptol, menthol, thymol, and several sesquiterpenes have been used as topical medication to control Varroa destructor mites and as nutraceutical compounds against Nosema spp. spores (Imdorf et al., 1999; Borges, Guzman-Novoa \& Goodwin, 2020). The anti-nosemosis properties of essential oils may result from the lipophilic nature and low molecular weight of their terpens/terpenoids. They can cause cell death or inhibit sporulation and germination of fungi by disrupting the cell membrane structure or inhibiting chitin polymerization of the cell wall (Nazaaro et al., 2017). The objective of the present study was to evaluate the effect of dietary supplements of native bee yeasts and essential oils from a native plant on honey bee health and immunity variables, as a possible strategy for preventing disease in bee colonies. We measured six critical variables in worker bees: survival, food intake, cumulative fat body percentage, and expression of three health- and immune-related genes ( $\mathrm{Vg}$, proPO, and GOx).

Newly emerged $A$. mellifera workers were fed nine artificial diets, five supplemented with yeasts isolated from a native bee Scaptotrigona pectoralis, three with essential oils from Mexican 
90 oregano Lippia graveolens, and the control diet; all potentially strengthen health and immune

91 function in $A$. mellifera. Honey bee health and immune function include complex metabolic

92 pathways; therefore, it is difficult to make assumptions about immunity based on relatively few

93 genes and health determinants. However, the response variables used in this study are critical

94 modulators of health in A. mellifera. Thus, it is feasible to expect that diets containing yeasts or

95 essential oils may enhance worker bee survival, induce higher food intake, cause significant

96 accumulation in the fat body, and produce higher expression of immune-related genes $(\mathrm{Vg}$,

97 proPO, and $G O x$ ).

98

99

100

101

102

103

104

105

106

107

108

109

110

111

112

\section{Materials \& Methods}

Bee-associated yeasts

We extensively sampled yeasts from $S$. pectoralis bee colonies in proximity to $A$. mellifera colonies. We isolated and purified all the cultivable yeast strains from the native bee colonies and stored them in $15 \%$ glycerol $(\mathrm{w} / \mathrm{w})$ at $-80{ }^{\circ} \mathrm{C}$, and identified a group of yeasts associated with larval food, bee bread, and honey that are promising supplements in bee nutrition (Lizama, 2011). Yeasts were identified by molecular methods using primers NL1-NL4 and sequencing the D1/D2 domain of the LSU 26S rDNA (Canto, Herrera \& Rodríguez, 2017). Of the resulting yeast strain consensus sequences, five strains were selected for use in this study: 1) CICY-RN358, identified as Starmerella bombicola, isolated from pots containing honey inside nests; 2) CICY-RN-386, identified as Starmerella etchellsii, isolated from pots containing larval food; 3) CICY-RN-413, identified as Starmerella bombicola 2, isolated from pots containing bee bread; 4) CICY-RN-443, identified as Zygosaccharomyces mellis, isolated from pots containing honey; and 5) CICY-RN-Sac2, S. cerevisiae a commercial strain used in diet formulations for feeding bees (see GeneBank accession numbers and nucleotide sequences in Appendix). 


\section{Essential oils}

114 Three types of EOs were extracted from L. graveolens. Commonly known as Mexican oregano,

115 this plant belongs to the family Verbenaceae and is distributed throughout the Yucatan

116 Peninsula (Martínez-Natarén et al., 2014). It produces three oil chemotypes called carvacrol,

117 thymol, and sesquiterpenes (Acosta-Arriola, 2011). The EOs were extracted from leaves

118 collected from cultivated crops and wild plant populations following Calvo-Irabién et al. (2014).

119 Chemical characterization of the EOs was done using a gas chromatographer coupled to a mass

120 spectrophotometer (GC-MS; Agilent Technologies Model 6890N). Chromatographer was

121 equipped with a 5875 B mass selective detector, a splitless injector, and an MS-Chemstation

122 GI701-DA data system incorporating the National Institute of Standards and Technologies

123 (NIST) spectrum library. An apolar column (5\% phenyl methylpolysiloxane; Agilent VF-5ms)

124 separated the oil compounds, which were classified into three chemotypes based on the dominant

125 compound: carvacrol, consisting of $66 \%$ carvacrol; thymol, containing $49 \%$ thymol; and,

126 sesquiterpenes, consisting of a mixture of four sesquiterpenes, $\beta$-caryophyllene (14.6 mg, 56\%),

$127 \alpha$-humulene (6.5 mg, 25\%), eucalyptol (1.8 mg, 7\%) and p-cymene (1.5 mg, 5.9\%) (Table 1).

128 Diets

129 Nine artificial diets were formulated for the experiment. The base diet was a simple pollen

130 substitute (base diet) prepared following standard methods for raising adult $A$. mellifera workers

131 in cages under laboratory conditions (Williams et al., 2013). The base diet was made on a

132 weight/weight basis following the formulation of van der Steen (2007): soy flour (14\%); beer

133 yeast flour (10\%); calcium caseinate flour (15\%); whey protein flour (4\%); sucrose solution

$134(48 \%, 1: 1 \mathrm{w} / \mathrm{v}$ in sterile tap water); and linseed oil $(9 \%)$. We replaced the beer yeast flour with

135 one of five yeast strains isolated from $S$. pectoralis colonies in the experimental yeast diets. 
136 Saccharomyces cerevisiae was included in the feeding experiment because it is widely used in

137 beekeeping for its significant protein and vitamin contributions. Yeasts were freeze-dried before

138 addition to diets and added 7\% (w/w) proportion to base formulation resulted in cell density of

139 approximately 539,155 cells/g. This cell density is similar to the observed in the sources from

140 which yeasts were isolated. The EOs diets consisted of the base formulation enriched with one of

141 the three L. graveolens chemotypes, classified according to their dominant phytochemical

142 compound, and contained no added yeast material. The EOs were added to the base formulation

143 at a $1 \%(\mathrm{w} / \mathrm{w})$ proportion.

144 Bees and experimental design

145 The bee source were 20 colonies of Africanized $A$. mellifera bees reared from five-frame nucleus

146 colonies in the experimental apiary of the Faculty of Veterinary Medicine and Zootechny

147 (Facultad de Medicina Veterinaria y Zootecnia) of the Autonomous University of Yucatan,

148 Mexico $\left(20^{\circ} 51^{\prime} 51.62^{\prime \prime} \mathrm{N} ; 8^{\circ} 36^{\prime} 45.35^{\prime \prime} \mathrm{W}\right)$. This apiary is surrounded by 28 hectares of dry

149 tropical forest containing at least 90 nectar- and pollen-producing plant species. The regional

150 climate is subtropical with a $25^{\circ} \mathrm{C}$ average annual temperature, $948 \mathrm{~mm}$ annual precipitation and

151 an elevation of $8 \mathrm{~m}$ amsl. During summer 2018, 1-2 frames containing worker pupae near

152 emergence were extracted from each of twelve colonies with sufficient worker brood frames (3-4

153 frames). These extracted frames were incubated in constant darkness at $36{ }^{\circ} \mathrm{C}$ air temperature,

$15470 \%$ relative humidity, and constant airflow to remove excess $\mathrm{CO}_{2}$ until adult workers emerged.

155 Newly emerged workers were collected after $48 \mathrm{~h}$ and placed in groups of 24-30 bees inside

156 individual cages (plastic containers, $11.0 \mathrm{~cm}$ x $7.5 \mathrm{~cm}$ x $9.0 \mathrm{~cm}$ ). Cages were randomly assigned

157 to one of the following treatments: A) S. bombicola diet; B) S. etchellsii diet; C) S. bombicola 2

158 diet; D) Z. mellis diet; E) S. cerevisiae diet; F) carvacrol diet; G) thymol diet; H) sesquiterpenes 
159 diet; and the base diet only (control). Cages were kept in constant darkness at $36{ }^{\circ} \mathrm{C}$ air

160 temperature, $70 \%$ relative humidity, and constant airflow to remove excess $\mathrm{CO}_{2}$ throughout the

161 experiment. Diets were supplied at $0.85 \pm 0.4 \mathrm{~g}$ per cage every three days, and feeders containing

162 old food replaced every three days to avoid fermentation or microbial degradation. In addition,

163 fresh, sterile water $(\sim 2.0 \mathrm{~g})$ was supplied daily to bees.

164 For each treatment, three cages were assigned to measure survival, another three measure fat

165 body accumulation, another three measure gene expression, and food intake was measured in all

166 cases as described below (Fig. 1). The diet was the main factor in the experimental design, and

167 we made paired comparisons between the control diet and the target diet (yeast or EO) to test the

168 effect of the diet. Time (day) and hoarding cages were set as random variables to estimate the

169 variance due to intrinsic differences within the factors of days and cages.

170 Survival

171 Cages assigned to measure survival were monitored for 12 days. Estimates of bee survival per

172 cage in the corresponding treatment were calculated by the number of living and dead bees per

173 cage per day during the 12-day experiment. These data were used to construct survival

174 probability curves and calculate median survival time, that is, the shortest time for which bee

175 survival was less than or equal to 0.5 . Dead individuals were removed daily to prevent

176 contamination.

177 Food intake

178 For all cages in all treatments, the average daily food intake per bee ( $\%$ food intake/bee/day) was

179 measured over nine days (Williams et al., 2013). Feeders were filled with the respective diet

180 type, weighed (initial mass), and placed in the corresponding cage. The time (h) each feeder was

181 placed in a cage and the number of alive bees in the cage (initial bees) were recorded. After three 
182 days, the feeders were removed, recording the time (final time) and the number of living bees in

183 the cage (final bees). Feeder weight (final mass) was measured and the total amount of food

184 consumed was calculated by subtracting final mass from initial mass. Average food evaporation

185 was estimated by placing control feeders in cages under the same conditions as the treatment

186 feeders but without bees. Food intake was calculated by subtracting the average evaporation

187 value from the observed differences in mass in the experimental diets. The time each feeder was

188 in a cage was calculated by subtracting the initial time from the final time. Hourly intake by cage

189 was calculated by dividing food intake mass by feeder time in the cage, and hourly intake per bee

190 was calculated by dividing hourly cage intake by the final number of living bees in a cage. Daily

191 bee intake was calculated by multiplying hourly bee intake by 24 .

192 Fat body

193 Accumulated fat body percentage per bees was measured following Wilson-Rich, Dres \& Starks

194 (2008). During nine days, at three-day intervals, a group of three bees was removed from each

195 cage. Bees were cold anesthetized, killed by separating the head from the abdomen, and

196 desiccated for three days at $24^{\circ} \mathrm{C}$ in silica gel. The abdomens were weighed individually (initial

197 mass) on an analytical balance (Ohaus ${ }^{\mathrm{TM}}$; $0.001 \mathrm{~g}$ accuracy), and soaked in diethyl ether for $24 \mathrm{~h}$

198 to dissolve all fatty tissue. They were dried for three days and weighed (final mass). Fat body

199 proportion per bee was calculated by dividing final abdomen mass by initial abdomen mass.

200 Vg, proPO, GOx gene expression

201 Expression of $V g$, proPO, and GOx in caged bees was measured by RT-qPCR. During nine days,

202 three bees were removed every three days from each cage, killed and dissected. Expressions of

$203 V g$ and $p r o P O$ were measured using abdomens and $G O x$ expression using heads. The abdomens

204 and heads were each pooled by cage, ground and homogenized in TRIzol ${ }^{\circledR}$ reagent (Invitrogen, 
205 USA) following manufacturer instructions for total RNA isolation. Genomic DNA

206 contamination was extracted from the samples using DNAse I (DNA-free kit, Ambion, USA),

207 and RNA concentration and purity measured with a NanoDrop ${ }^{\circledR}$ ND-1000 spectrophotometer

208 (Thermo Scientific NanoDrop Technologies, LLC, Wilmington, DE, USA). Quality of the RNA

209 was checked by electrophoresis in agarose gel (1.5\%). A well-established, in-house protocol was

210 used to produce single-strand complementary DNA (cDNA) from 300 ๆg purified RNA of each

211 sample by reverse transcription using a final concentration of $50 \mathrm{U} / \mu \mathrm{L}$ MultiScribe ${ }^{\mathrm{TM}}$ Reverse

212 Transcriptase (Invitrogen/Life Technologies, CA, USA). Synthesis of cDNA was done at $42{ }^{\circ} \mathrm{C}$

213 for $50 \mathrm{~min}$. The first-strand cDNA was analyzed by RT-qPCR using primers for $\mathrm{Vg}$, proPO,

$214 G O x$, and the RPS5 reference gene. A 150-bp Vg amplicon was generated with

215 NM_001011578.1-F (5'- GTTGGAGAGCAACATGCAGA-3') and NM_001011578.1-R (3'-

216 TCGATCCATTCCTTGATGGT-5') (Tsuruda, Amdam \& Page, 2008). We developed an

217 enzyme-specific primer pair for the present study and used it to generate a 130-bp proPO

218 amplicon with the Primer Express ver. 3 software (Applied Biosystems, Foster City, CA, USA):

219 AY242387.2-F (5'-GAACGGCTATGTAATCGTCTTGGA-3') and AY242387.2-R (3'-

220 TACCGCTGGGTCGAAATGG-5'). A 201-bp GOx amplicon was generated with AB022907.1-

221 F (5'-GAGCGAGGTTTCGAATTGGA-3') and AB022907.1-R (3'-

222 GTCGTTCCCCCGAGATTCTT-5') (Yang \& Cox-Foster, 2005). One pair of internal reference

223 primers was used for generating a 115-bp amplicon of ribosomal protein S5 (reference gene

224 RPS5): XM_006570237.2-F (5'- AATTATTTGGTCGCTGGAATTG-3') and XM_006570237.2-

225 R (3'-TAACGTCCAGCAGAATGTGGTA-5') (Evans, 2006). Analysis by RT-qPCR was run

226 with a thermocycler StepOne ${ }^{\mathrm{TM}}$ Real-Time PCR System using the StepOne ver. 2.3 software

227 (Applied Biosystems). Each sample per cage was run in three internal replicates, which were 
228 analyzed with RT-qPCR using a 48-well PCR plate. Amplification of cDNA was done using

229 SYBR Green Master Mix as a detection signal (Applied Biosystems), $2 \mu \mathrm{L}$ cDNA, and $4 \mu \mathrm{M}$ of

230 each gene-specific primer at a $0.4 \mu \mathrm{M}$ concentration in a $20 \mu \mathrm{L}$ reaction volume. Amplification

231 runs were: $95^{\circ} \mathrm{C}$ for $3 \mathrm{~min}$; and 40 cycles of $95^{\circ} \mathrm{C}$ for $30 \mathrm{~s}, 58^{\circ} \mathrm{C}$ for $30 \mathrm{~s}$ and $72{ }^{\circ} \mathrm{C}$ for $1 \mathrm{~min}$.

232 The specificity and accuracy of the RT-qPCR products for all samples were verified with melting

233 curve analysis. Relative expression levels (REL) of the $V g$, proPO, and $G O x$ genes were

234 calculated using the comparative $\mathrm{C}_{\mathrm{T}}\left(\Delta \Delta \mathrm{C}_{\mathrm{T}}\right)$ method (Schmittgen \& Livak, 2008). The relative

235 quantification of the target genes was normalized to RPS5 expression. The RT-qPCR conditions,

236 following MIQE guidelines, are described in the Appendix.

237 Data analysis

238 Data from Day 0 are shown in the figures but were excluded from statistical analyses. On Day 0, 239 the first dose of food was provided at different times (1-3 h), but feeding was done within a 30-

240 min margin of difference during the remainder of the experimental period. The data were tested

241 for normality (Kolmogorov-Smirnov test), homogeneity of variance (Levene test), and

242 transformed if needed before statistical analysis. The worker bee survival curve and median

243 survival time were compared between the control (base diet) and each diet treatment using the

244 non-parametric Kaplan-Meier survival analysis and the Log-Rank test. Survival curves for each

245 treatment were built with the survival (Therneau, 2019) and the survminer (Kassambara \&

246 Kosinski, 2019) packages in the R software (RStudio Team, 2006). In each treatment, the

247 Kaplan-Meier estimator was applied to calculate the probability that an individual bee would

248 survive at a particular time. The Log-Rank test compared survival probability in a specific

249 treatment with survival time in the control. 
250 To statistically test the effect of the diet on food intake (square-root transformed), fat body

251 accumulation (not transformed), and expression (REL Log10-transformed) of the Vg, proPO,

252 and GOx genes, we used Linear Mixed Effects Models (LMM) and planned contrasts to test

253 specific hypotheses about differences between the control and each of the diets (Shad et al.

254 2019). Analyses were conducted in the lmerTest package (Kuznetsova, Brockhoff \& Christensen,

255 2019) in the R System for Statistical Computing (R Core Team, 2018). The maximum likelihood

256 fitted the LMM with the lmer function, and the sum of squares of Type III for unbalanced

257 designs was used to calculate F and $\mathrm{p}$ values. The Satterthwaite's method was applied for

258 approximating effective degrees of freedom. Diet type was established as a fixed factor and day

259 and cage as random variables. The analysis was based on the following model with no

260 interaction: response variable $=$ diet type $+(1 \mid$ day $)+(1 \mid$ cage $)$. Orthogonal contrasts were applied

261 to compare each of the eight diets with the control using the contest function. Dunnett test was

262 used to compare each treatment to the control, and the Kenward-Roger's method to approximate

263 degrees of freedom.

\section{Results}

265 Survival

266 Although worker bee survival in all treatments had lower survival probability curves (Fig. 2)

267 than in the control, the curves did not statistically differ (Kaplan-Meier, Log-Rank test, $\mathrm{p}>0.05$ ).

268 However, median survival time (black dashed line, Fig. 2) did tend to be lower in bees fed the

269 carvacrol (median $=3$ days) and sesquiterpenes (median $=3$ days) treatments than in those fed

270 the control (median $=4$ days $)$.

271 Food intake 
272 Diet type affected average daily food intake per bee $\left(\mathrm{LMM}, \mathrm{F}_{8,288}=2.54, \mathrm{p}=0.0109\right.$, Fig. 3).

273 The estimation of random variables identified a greater variation between days but lower

274 variation between cages $($ Day $=37.01 \%$, Cage $=15.58 \%)$. Food intake was higher in the $Z$.

275 mellis (mean $\pm \mathrm{SD}=1.34 \pm 1.48 \%$, post-hoc Dunnett test, $\mathrm{p}=0.0089)$ and S. cerevisiae $(\mathrm{mean} \pm$

$276 \mathrm{SD}=1.41 \pm 2.52 \%$, post-hoc Dunnett test, $\mathrm{p}=0.0456)$ diets than in the control. In the other

277 yeast and EOs treatments food intake was similar to the control (mean $\pm \mathrm{SD}=0.76 \pm 0.48 \%$,

278 post-hoc Dunnett test, $\mathrm{p}>0.05)$.

279 Fat body

280 Fat body accumulation was significantly affected by diet type (LMM, $\mathrm{F}_{8,270}=3.08, \mathrm{p}=0.0024$,

281 Fig. 4) and variation due to days and cages was relatively lower (Day $=1.28 \%$, Cage $=5.80 \%$ ).

282 In the yeast diets, fat body accumulation did not differ from the control (mean $\pm \mathrm{SD}=50.10 \pm$

$28317.15 \%$, post-hoc Dunnett test, $\mathrm{p}>0.05$ ), but two EOs treatments had a significant negative

284 effect on fat body accumulation compared to the control: thymol (mean $\pm \mathrm{SD}=32.68 \pm 12.60 \%$,

285 post-hoc Dunnett test, $\mathrm{p}=0.0001)$ and sesquiterpenes (mean $\pm \mathrm{SD}=38.11 \pm 14.90 \%$, post-hoc

286 Dunnett test, $\mathrm{p}=0.0373$ ). Fat body accumulation in the other yeast diets and in the carvacrol diet

287 did not differ from the control (mean $\pm \mathrm{SD}=43.02 \pm 13.83 \%$, post-hoc Dunnett test, $\mathrm{p}=$

2880.3280$,

289 Expression levels of the $\mathrm{Vg}$, proPO, and GOx genes

290 Gene expression was highest on day six for $V g$, proPO, and GOx, both in the yeast and EOs

291 treatments. Diet affected expression of the $V g$ gene $\left(\mathrm{LMM}, \mathrm{F}_{8,78}=18.04, \mathrm{p}<0.0001\right.$, Fig. 5) and

292 variation was substantial between days but null in response to cage (Day $=96.15 \%)$. Compared

293 to the control, $V g$ expression was lower in the carvacrol (mean $\pm \mathrm{SD}=17.96 \pm 12.68 \mathrm{REL}$, post-

294 hoc Dunnett test, $\mathrm{p}<0.0001)$ and thymol treatments (mean $\pm \mathrm{SD}=17.03 \pm 9.72 \mathrm{REL}$, post-hoc 
295 Dunnett test, $\mathrm{p}<0.0001)$. In contrast, the relative expression of the $V g$ gene was similar to the

296 control in the yeast diets and the sesquiterpenes diet (mean $\pm \mathrm{SD}=27.76 \pm 17.29 \mathrm{REL}$, post-hoc

297 Dunnett test, $\mathrm{p}>0.05)$.

298 Diet affected expression of the proPO gene (LMM, $\mathrm{F}_{8,78}=14.68, \mathrm{p}<0.0001$, Fig. 6) and

299 variation in gene expression was greater between days and negligible between cages (Day =

$30085 \%$ ). Expression of the proPO gene in the $S$. bombicola (mean $\pm \mathrm{SD}=8.41 \pm 6.37$ REL, post-

301 hoc Dunnett test, $\mathrm{p}=0.0224$ ), carvacrol (mean $\pm \mathrm{SD}=5.83 \pm 3.27$ REL, post-hoc Dunnett test, $\mathrm{p}$

$302<0.0001)$ and thymol (mean $\pm \mathrm{SD}=7.20 \pm 4.26 \mathrm{REL}$, post-hoc Dunnett test, $\mathrm{p}=0.0013$ )

303 treatments was lower than in the control. In the other yeast treatments and in the sesquiterpenes

304 treatment gene expression was similar to the control (mean $\pm \mathrm{SD}=12.44 \pm 8.90 \mathrm{REL}$, post-hoc

305 Dunnett test, $\mathrm{p}>0.05)$.

306 Diet affected expression of the $G O x$ gene $\left(\mathrm{LMM}, \mathrm{F}_{8,78}=22.73, \mathrm{p}<0.0001\right.$, Fig. 7$)$ and variation

307 in gene expression was higher between days and negligible between cages (Day $=83.60 \%$ ). The

308 yeast diets $S$. bombicola (mean $\pm \mathrm{SD}=7.89 \pm 3.88$ REL, post-hoc Dunnett test, $\mathrm{p}=0.0046$ ) and

309 S. etchellsii (mean $\pm \mathrm{SD}=8.10 \pm 4.43$ REL, post-hoc Dunnett test, $\mathrm{p}=0.0090)$ resulted in a

310 moderate reduction in gene expression, but the carvacrol (mean $\pm \mathrm{SD}=4.23 \pm 2.06 \mathrm{REL}$, post-

311 hoc Dunnett test, $\mathrm{p}<0.0001$ ) and thymol (mean $\pm \mathrm{SD}=2.79 \pm 1.76$ REL, post-hoc Dunnett test,

$312 \mathrm{p}<0.0001)$ treatments resulted in the strongest negative effect on gene expression compared to

313 the control. In the rest of the yeast diets and in the sesquiterpenes diet, GOx expression was

314 similar to the control (mean $\pm \mathrm{SD}=11.38 \pm 6.28 \mathrm{REL}$, post-hoc Dunnett test, $\mathrm{p}>0.05$ ).

\section{Discussion}

316 Survival 
317 The low worker survival observed in all the diets, including the control, suggests an

318 undocumented factor that probably shortened lifespan in the caged bees. One possible cause is

319 the amount of protein in all the diets. Nitrogen-rich diets (protein or amino acids) have

320 deleterious effects on survival, resulting in surprisingly high mortality in caged honey bees (Pirk

321 et al., 2010; Archer et al., 2014; Gregorc et al., 2019). The underpinning mechanism for this is

322 unclear, but nitrogen-rich diets may increase oxidative stress by overproducing reactive oxygen

323 species (ROS). Diets with a 1:5 protein:carbohydrate ratio strongly reduce survival in caged

324 honey bees (Archer et al., 2014), and the ratio in the present study was approximately 1:1; this is

325 a large amount of nitrogen for bees and may explain the low survival rates. Further research

326 directly addressing the harmful effects of dietary protein on bee lifespan are needed.

327 The specific yeasts used here exhibited a positive effect on bee survival. This suggests that yeasts

328 naturally associated with bee colony food reserves do not diminish bee health when used as food

329 compounds. When added to pollen, brewers' yeast (S. cerevisiae) positively affects colony-level

330 fitness components such as brood-rearing (Herbert \& Shimanuki, 1978; van der Steen, 2007).

331 Pioneering studies using caged bees found that using brewers' yeasts in bee food resulted in

332 survival rates similar to those in bees fed pollen (Standifer et al., 1960). Recent studies have

333 found that addition of brewers' yeasts to pollen substitutes can maintain bee longevity in cage

334 conditions, resulting in survival rates similar to those observed in bees fed bee bread (Smodiš

335 Škerl \& Gregorc, 2014; Esanu, Radu-Rusu \& Pop, 2018; Amro, Younis \& Ghania, 2020). These

336 studies and our results suggest that the nutrients provided by bee-associated yeasts are a good

337 food source for bees and could further improve bee health.

338 Except for the sesquiterpenes treatment, the EOs treatments negatively impacted worker bee

339 survival. The carvacrol and thymol treatments may have been somewhat toxic to the bees since 
340 they are xenobiotics and are not naturally present in bee diets. These results coincide with

341 previous findings indicating that diets containing carvacrol and thymol reduce survival in honey

342 bees (Maistrello et al., 2008; Borges, Guzman-Novoa \& Goodwin, 2020). Moreover, high

343 mortality rates have been reported in caged bees in response to increases in carvacrol and thymol

344 concentrations in feeding treatments (Glavan et al., 2020). Carvacrol and thymol are promising

345 monoterpenoids as treatments against Nosema fungi and parasitic Varroa mites in honey bee

346 colonies (Imdorf et al., 1999; Borges, Guzman-Novoa \& Goodwin, 2020). Therefore, evaluating

347 their effects on bee survival is essential to quantify their toxicity (Ebert et al., 2007; Gashout \&

348 Guzman-Novoa, 2009; Glavan et al., 2020). For example, thymol is approved in Europe (EC,

349 2007) for controlling $V$. destructor in bee colonies because it has low toxicity in evaporation

350 treatments. However, feeding and topical assays are needed to construct a complete toxicity

351 spectrum. There is no current evidence of the harmful effects of sesquiterpenes on bee survival.

352 The thymol and carvacrol concentrations in the sesquiterpenes diet were much lower than in the

353 other two EOs treatments.

354 Based on the present results, bee-associated yeasts seem to be suitable natural elements for

355 sustained laboratory feeding of bees, with no negative impacts on survival. However, using EOs

356 from L. graveolens in bee diets requires more research to evaluate the effect of different

357 concentrations in feeding experiments under laboratory and colony conditions.

358 Food intake

359 Under laboratory conditions, worker bee food intake can decrease in response to handling

360 practices, stress due to confinement and artificial feeding (Even, Devaud \& Barron, 2012).

361 However, in the present study, food intake was similar to field conditions, suggesting that the

362 bees ingested sufficient food to maintain their physiological processes. 
363 The high food intake in the Z. mellis and $S$. cerevisiae diets coincided with vigorous food intake

364 of $S$. cerevisiae-enriched diets reported in caged bees in another study (Amro, Younis \& Ghania,

365 2020) and was similar to food intake in honey bee colonies under field conditions (Sihag \&

366 Gupta, 2011). High food intake of the two yeast-supplemented diets may be due to the nutritional

367 components contained in yeast cells (e.g., lipids or proteins) (Herbert, Shimanuki \& Caron,

368 1977) and/or the volatiles produced by microbial metabolism (Christiaens et al., 2014). Food

369 intake in the present EOs treatments was similar to that reported when using different thymol

370 concentrations compared to a base diet of sucrose syrup (Maistrello et al., 2008; Costa, Lodesani

$371 \&$ Maistrello, 2010). In another study, food intake containing different concentrations of thymol

372 and carvacrol did not change compared to a control (Borges, Guzman-Novoa \& Goodwin, 2020).

373 Therefore, supplementation of bee diets with EOs does not affect palatability.

374 Fat body

375 Supplementation with yeasts or EOs did not increase fat body accumulation in bee abdomens,

376 although fatty tissue content remained unchanged throughout the experiment in the yeast

377 treatments. Previous research has focused on evaluating how pollen, the source of protein and

378 lipids for bees, can influence bees' accumulation of fatty tissue. For instance, diets containing

379 pollen tend to increase fat body reserves more than sugar-rich diets (Barragán, Basualdo \&

380 Rodriguez, 2015) and variations in pollen quality can affect the fat body. For example, in one

381 study, fatty tissue was higher in bees fed polyfloral pollen than in fed monofloral pollen, despite

382 similar feed intake (Alaux et al., 2011).

383 The present results indicate that the yeast supplements helped to maintain fat body mass

384 constant. Yeast-enriched formulations contain the amount of lipids and proteins needed for a

385 constant fat body accumulation (Di Pasquale et al., 2013). Additionally, the higher food intake 
386 observed in two of the yeast treatments can provide the bees a surplus of nutrients for their

387 metabolism, allowing a constant fat body accumulation, which is critical since caged honey bees

388 can experience a drastic reduction in abdominal fat tissue (Toth et al., 2005).

389 Our results confirm previous reports of the pre-existing fat body reserves in newly emerged bees

390 (i.e., Day 0; Ramsey et al. 2019), probably accumulated during the larval and pupal stages.

391 Furthermore, most examined bees exhibited similar fatty tissue percentages, indicating that they

392 had the resources required to produce anti-pathogen molecules immediately after emerging

393 (Wilson-Rich, Dres \& Starks, 2008).

394 Expression levels of $\mathrm{Vg}$, proPO, and GOx genes

395 The expression of the $\mathrm{Vg}$, proPO, and $G O x$ genes was relatively unaffected in the yeast

396 treatments but reduced in the carvacrol and thymol treatments. The $V g$ expression pattern did not

397 differ between the diet types, even at the highest levels at day six. This kind of $V g$ profile is to be

398 expected during the first week of development in nurse bees because they need a higher amount

399 of vitellogenin at this life stage to synthesize royal jelly to feed the brood and queen (Bitondi \&

400 Simões, 1996). However, vitellogenin synthesis can be nutritionally regulated using protein-rich

401 diets, thus, the expression of the $V g$ gene. Although pollen and bee bread are good diets for

402 stimulating Vg expression and titers (Cremonez, De Jong \& Bitondi, 1998; Di Pasquale et al.,

403 2016), pollen substitute diets containing native yeasts can also provide this stimulation. For

404 example, bees fed a diet containing yeasts and soybean exhibited $V g$ levels similar to bees fed

405 bee bread (Cremonez, De Jong \& Bitondi, 1998). However, in another study, bees fed yeast and

406 soybean supplemented diets had lower $V g$ levels than naturally fed bees in a colony (Bitondi \&

407 Simões, 1996). In addition, bees fed a fermented pollen substitute containing bee bread-

408 associated microorganisms (bacteria and yeasts) promoted $V g$ levels similar to those in bees fed 
409 on bee bread, indicating that bee-associated microbes can help to enrich artificial food (Dias et

410 al., 2018). Although further research is needed, the present results suggest that bee associated-

411 yeasts may be a safe protein source for maintaining healthy $V g$ levels and a promising pollen

412 substitute in artificial diets.

413 We observed that supplementation with carvacrol and thymol induced down-regulation of $V g$. Its

414 expression is known to be low in adult bees exposed to thymol vapors (Boncristiani et al., 2012),

415 and expression is delayed in bee larvae fed diets containing thymol (Charpentier et al., 2013).

416 Alterations in $\mathrm{Vg}$ expression are critical to bees because this protein influences many life-history

417 traits and is connected to immune function via nutrition (Amdam et al., 2004). Negative impacts

418 on $V g$ expression may explain the low median survival time observed in the carvacrol treatment

419 since reduced $\mathrm{Vg}$ levels result in a reduced lifespan. In addition, changes in hormone metabolism

420 may be responsible for $V g$ down-regulation in response to thymol exposure (Boncristiani et al.,

421 2012). Further data on carvacrol or sesquiterpenes on $V g$ expression are needed because these

422 EOs components are valuable for controlling pathogens in apiculture (Borges, Guzman-Novoa \&

423 Goodwin, 2020).

424 Regardless of diet type, the overall pattern of proPO expression differed from that of $\mathrm{Vg}$ and

$425 G O x$, exhibiting a gradual increase until day six with a slight reduction by day nine. In worker

426 bees, proPO expression reaches a plateau within the first week of adult life and remains similar

427 from nurse to forager stages, with very slight variability (Lourenço et al., 2005; Schmid et al., 428 2008).

429 Immune function in insects is costly in nutrients and energy, dependent on protein intake (Lee,

430 Simpson \& Wilson, 2008). Since prophenoloxidase in bees is an enzyme (i.e. protein), this same

431 dynamic can be expected in the proPO (gene-enzyme) system. However, there are no previous 
432 reports of an evident influence of nutrition on proPO expression in bees. However, proPO

433 expression is positively influenced by protein-rich diets in model insects such as Spodoptera

434 littoralis and Anabrus simplex (Srygley et al., 2009; Cotter et al., 2019). Of the yeast treatments,

435 only $S$. cerevisiae caused any up-regulation of proPO expression. This is not entirely unexpected

436 since this yeast has long been marketed as a high protein- and vitamin-content dietary

437 supplement for bees (Standifer et al., 1960). The carvacrol and thymol treatments induced lower

438 proPO expression. Expression of proPO in adult worker bees is linked to dietary diversity

439 (Alaux et al., 2010), but EOs are xenobiotics and not part of the natural bee diet. This suggests

440 that EOs may act on gene expression in other ways, possibly blocking additional activation

441 factors needed to regulate proPO expression tight or activating detoxification pathways

442 (Berenbaum \& Johnson, 2015). The proPO system is the first line of humoral response in bees,

443 and it regulates cellular immune responses. In the present study, the reductions in gene

444 expression caused by carvacrol and thymol could increase individual susceptibility to pathogens

445 such as Nosema and viruses, eventually weakening the entire colony. Even though carvacrol and

446 thymol reduce proPO expression, they have also been shown to reduce Nosema spores

447 (Maistrello et al. 2008; Costa, Lodesani \& Maistrello 2010; Borges, Guzman-Novoa \& Goodwin 448 2020).

$449 G O x$ expression patterns were initially undetectable in emerging bees in all the treatments, but 450 gradually increased with age. This coincides with previous findings that $G O x$ expression and 451 glucose oxidase secretion in hypopharyngeal glands are age-dependent and attain the highest 452 levels in old nurse bees and foragers (Takenaka et al., 1990). In addition, expression of GOx may

453 be nutritionally dependent (Bucekova et al., 2014); for instance, GOx levels are higher in bees

454 fed polyfloral pollen than those fed monofloral or sugar diets (Alaux et al., 2011). This is 
455 supported by research using a Spodoptera exigua model in which high GOx levels were only

456 observed in insects fed an artificial diet (Merkx-Jacques \& Bede, 2005).

457 The yeast treatments slightly negatively affected GOx, although different cell densities or yeast

458 strain cocktails may produce different responses. There is no research to date on bee-associated

459 yeast in pollen substitutes as nutritional modulators of GOx. However, one study did find that the

460 hypopharyngeal glands, the main GOx synthesis site (Ohashi, Natori \& Kubo, 1999), were

461 stimulated in bees after being fed a pollen substitute containing the yeast Candida tropicalis

462 (Amro, Younis \& Ghania, 2020).

463 Both the carvacrol and thymol diets caused reduced $G O x$ expression. The observed low $G O x$

464 expression was probably due to a toxicity effect from carvacrol and thymol, which can be

465 expected considering these compounds act as xenobiotics. Diets with added EOs containing

466 carvacrol or thymol as dominant compounds may trigger detoxification mechanisms in bees.

467 Detoxification would limit the resources available for $G O x$ transcription. Further evaluation is

468 needed to confirm this possibility by testing the responses of variables related to xenobiotic

469 detoxification pathways in honey bees (Berenbaum \& Johnson, 2015). Any possible adverse

470 effect of carvacrol and thymol on $G O x$ levels deserves further attention since it can negatively

471 affect bee capacity to sterilize brood food and honey, potentially making entire colonies more

472 susceptible to pathogen attack.

\section{Conclusions}

474 Although the present results do not conclusively demonstrate that diets enriched with bee-

475 associated yeasts directly benefit bee health, they do show they can maintain bee survival, are

476 palatable to bees, and maintain fat body accumulation in bees. Furthermore, diets enriched with

477 yeasts can keep immune-related genes within an acceptable and optimal range of expression; for 
478 instance, adding $S$. cerevisiae to the bee diet can upregulate proPO expression. Future research 479 on yeast-supplemented diets needs to explore different cell densities and yeast cocktails and 480 evaluate yeasts' antagonistic potential towards intestinal pathogens such as Nosema spp. Even 481 when the EOs diets did not significantly decrease bee survival and food intake, the notable 482 adverse effects of the carvacrol and thymol treatments on fat body accumulation and expression 483 of the $V g$, proPO, and $G O x$ genes suggest that these EOs can imprint stress on bees, possibly 484 affecting bee health. Our findings encourage further analysis of EOs under laboratory and in-hive 485 conditions to identify and quantify their impacts, and adjust their application and management in 486 beekeeping to enhance honey bee health. Our study contributes to understanding native yeasts and EOs as nutritional modulators of bee health as strategies for improving health and immune function in A. mellifera colonies.

\section{Acknowledgements}

The authors thank Rodolfo Iuit, Víctor Iuit and Filiberto Bacab for technical assistance in the apiaries; Luis Simá and Gabriel Dzib for sampling and collecting plant material to obtain essential oils; Matilde Ortíz for technical support in the molecular biology laboratory; and Dr.

Edén Magaña-Gallegos for support in fabricating environmental controllers for the experimental area. We thank the anonymous reviewers, Daniel Borges, and Jorge Navarro for their careful reading of the manuscript and their many insightful corrections, comments, and suggestions, especially in statistics. This study was supported by the CONACYT (219922). Canché-Collí received a CONACYT scholarship (374928/242994).

\section{References}


499

500

501

502

503

504

505

506

507

508

509

510

511

512

513

514

515

516

517

518

519

520

521

Acosta-Arriola V. 2011. Variación en la composición química del aceite esencial de Lippia graveolens, en poblaciones silvestres de Yucatán, y su relación con factores edafoclimáticos. MSc thesis, Centro de Investigación Científica de Yucatán, A.C.

Alaux C, Dantec C, Parrinello H, Le Conte Y. 2011. Nutrigenomics in honey bees: digital gene expression analysis of pollen's nutritive effects on healthy and varroa-parasitized bees. BMC Genomics 12:496 https://doi.org/10.1186/1471-2164-12-496

Alaux C, Ducloz F, Crauser D, Le Conte Y. 2010. Diet effects on honey bee immunocompetence. Biology Letters 6(4):562-565 https://doi.org/10.1098/rsb1.2009.0986

Amdam GV, Simões ZLP, Hagen A, Norberg K, Schrøder K, Mikkelsen Ø, Kirkwood TBL, Omholt SW. 2004. Hormonal control of the yolk precursor vitellogenin regulates immune function and longevity in honey bees. Experimental Gerontology 39(5):767-773 https://doi.org/10.1016/j.exger.2004.02.010

Amro A, Younis M, Ghania A. 2020. Physiological effects of some pollen substitutes diets on caged honey bee workers (Apis mellifera L.). International Journal of Environment 9(1):87-99 https://doi.org/10.3126/ije.v9i1.27589

Archer CR, Köhler A, Pirk CWW, Oosthuizen V, Apostolides Z. 2014. Antioxidant supplementation can reduce the survival costs of excess amino acid intake in honeybees. Journal of Insect Physiology 71:78-86 https://doi.org/10.1016/j.jinsphys.2014.10.006

Barragán S, Basualdo M, Rodríguez EM. 2016. Conversion of protein from supplements into protein of hemolymph and fat bodies in worker honey bees (Apis mellifera L). Journal of Apicultural Research 54(4):399-404. http://doi.org/10.1080/00218839.2016.1158534

Berenbaum MR, Johnson RM. 2015. Xenobiotic detoxification pathways in honeybees. Current Opinion in Insect Science 10: 51-58 https://doi.org/10.1016/j.cois.2015.03.005 
522 Bernklau E, Bjostad L, Hogeboom A, Carlisle A, Arathi HS. 2019. Dietary phytochemicals, 523 honey bee longevity and pathogen tolerance. Insects 10(1):1-14.

524 https://doi.org/10.3390/insects 10010014

525 Bitondi M, Simões Z. 1996. The relationship between level of pollen in the diet, vitellogenin and 526 juvenile hormone titres in Africanized Apis mellifera workers. Journal of Apicultural Research 35(1):27-36. https://doi.org/10.1080/00218839.1996.11100910

Borges D, Guzman-Novoa E, Goodwin PH. 2020. Control of the microsporidian parasite Nosema ceranae in honey bees (Apis mellifera) using nutraceutical and immunostimulatory compounds. PLOS One 15:e0227484. https://doi.org/10.1371/journal.pone.0227484

Bucekova M, Valachova I, Kohutova L, Prochazka E, Klaudiny J, Majtan J. 2014. Honey bee glucose oxidase-its expression in honey bee workers and comparative analyses of its content and $\mathrm{H}_{2} \mathrm{O}_{2}$-mediated antibacterial activity in natural honeys. Naturwissenschaften 101:661-670. https://doi.org/10.1007/s00114-014-1205-z

Calvo-Irabién LM, Parra-Tabla V, Acosta-Arriola V, Escalante-Erosa F, Díaz-Vera L, Dzib GR, Peña-Rodríguez LM. 2014. Phytochemical diversity of the essential oils of Mexican Oregano (Lippia graveolens Kunth) populations along an Edapho-climatic gradient. Chemistry \& Biodiversity 11(7):1010-1021 https://doi.org/10.1002/cbdv.201300389 
544 Canto A, Herrera CM, Rodríguez R. 2017. Nectar-living yeasts of a tropical host plant

545 community: diversity and effects on community-wide floral nectar traits. PeerJ 5:e3517

$546 \quad$ https://doi.org/10.7717/peerj.3517

547 Charpentier G, Vidau C, Ferdy J, Tabart J, Vetillard A. 2013. Lethal and sub-lethal effects of 548 thymol on honey bee (Apis mellifera) larvae reared in vitro. Pest Management Science

$549 \quad 70(1): 140-147$ https://doi.org/10.1002/ps.3539

550 Christiaens JF, Franco LM, Cools TL, De Meester L, Michiels J, Wenseleers T, Hassan BA,

551 Yaksi E, Verstrepen KJ. 2014. The fungal aroma gene ATF1 promotes dispersal of yeast

552 cells through insect vectors. Cell Reports 9(2):425-432

$553 \quad$ https://doi.org/10.1016/j.celrep.2014.09.009

554 Costa C, Lodesani M, Maistrello L. 2010. Effect of thymol and resveratrol administered with 555 candy or syrup on the development of Nosema ceranae and on the longevity of honey bees

556 (Apis mellifera L.) in laboratory conditions. Apidologie 41:141-150.

557 https://doi.org/10.1051/apido/2009070

558 Cotter SC, Reavey CE, Tummala Y, Randall JL, Holdbrook R, Ponton F, Simpson SJ, Smith JA,

559 Wilson K. 2019. Diet modulates the relationship between immune gene expression and

560 functional immune responses. Insect Biochemistry and Molecular Biology 109:128-141

$561 \quad$ https://doi.org/10.1016/j.ibmb.2019.04.009

562 Cremonez TM, De Jong D, Bitondi MMG. 1998. Quantification of hemolymph proteins as a fast 563 method for testing protein diets for honey bees (Hymenoptera: Apidae). Journal of Economic Entomology 91(6):1284-1289 https://doi.org/10.1093/jee/91.6.1284 
565 Di Pasquale G, Alaux C, Le Conte Y, Odoux J, Pioz M, Vaissiere BE, Belzunces LP, Decourtye

566 A. 2016. Variations in the availability of pollen resources affect honey bee health. PLOS

567 One 11(9):e0162818 https://doi.org/10.1371/journal.pone.0162818

568

569

570

571

572

573

574

575

576

577

578

579

580

581

582

583

584

585

586

587

Di Pasquale G, Salignon M, Le Conte Y, Belzunces LP, Decourtye A, Kretzschmar A, Suchail S, Brunet JL, Alaux C. 2013. Influence of pollen nutrition on honey bee health: do pollen quality and diversity matter? PLOS One 8:e72016.

https://doi.org/10.1371/journal.pone.0072016

Dias JMA, Morais, MM, Francoy TM, Pereira RA, Turcatto AP, De Jong D. 2018. Fermentation of a pollen substitute diet with beebread microorganisms increases diet consumption and hemolymph protein levels of honey bees (Hymenoptera, Apidae). Sociobiology 65(4):760765 https://doi.org/10.13102/sociobiology.v65i4.3293

Ebert TA, Kevan PG, Bishop BL, Kevan SD, Downer RA. 2007. Oral toxicity of essential oils and organic acids fed to honey bees (Apis mellifera). Journal of Apicultural Research 46(4):220-224 http://dx.doi.org/10.1080/00218839.2007.11101398

EC. 2007. Council Regulation N. 834/2007 of 28 June 2007 on organic production and labelling of organic products and repealing Regulation (EEC) N. 2092/91, Official Journal of the European Union L189, 20.07.2007, pp. 1-23.

Erler S, Moritz RFA. 2016. Pharmacophagy and pharmacophory: mechanisms of self-medication and disease prevention in the honey bee colony (Apis mellifera). Apidologie 47(3):389-411 https://doi.org/10.1007/s13592-015-0400-Z

Esanu DI, Radu-Rusu CG, Pop IM. 2018. The use of some supplementary feeds and their influence on the longevity and wax production of caged honey bees. Scientific Papers. Series D. Animal Science 61(2):68-73. 
588 Evans JD. 2006. Beepath: An ordered quantitative-PCR array for exploring honey bee immunity

589 and disease. Journal of Invertebrate Pathology 93(2):135-139

$590 \quad$ https://doi.org/10.1016/j.jip.2006.04.004

591 Even N, Devaud J, Barron AB. 2012. General stress responses in the honey bee. Insects 3:12711298. https://doi.org/10.3390/insects3041271

593

594

595

596

597

598

599

600

601

602

603

604

605

606

607

608

609

610

Gashout HA, Guzmán-Novoa E. 2009. Acute toxicity of essential oils and other natural compounds to the parasitic mite, Varroa destructor, and to larval and adult worker honey bees (Apis mellifera L.). Journal of Apicultural Research and Bee World 48(4): 263-269 https://doi.org/10.3896/IBRA.1.48.4.06

Gilliam M. 1979. Microbiology of pollen and bee bread: The yeasts. Apidologie 10(1):43-53 https://doi.org/10.1051/apido:19790106

Glavan G, Novak S, Bozic J, Kokalj AJ. 2020. Comparison of sublethal effects of natural acaricides carvacrol and thymol on honey bees. Pesticide Biochemistry and Physiology 166:104567 https://doi.org/10.1016/j.pestbp.2020.104567

González-Santoyo I, Córdoba-Aguilar A. 2012. Phenoloxidase: a key component of the insect immune system. Entomologia Experimentali et Applicata 142:1-16 https://doi.org/10.1111/j.1570-7458.2011.01187.x

Goulson D, Nicholls E, Botías C, Rotheray E. 2015. Bee declines driven by combined stress from parasites, pesticides, and lack of flowers. Science 347(6229):1255957 https://doi.org/10.1126/science.1255957

Gregorc A, Sampson B, Knight PR, Adamczyk J. 2019. Diet quality affects honey bee (Hymenoptera: Apidae) mortality under laboratory conditions, Journal of Apicultural Research 58(4): 492-493 https://doi.org/10.1080/00218839.2019.1614736 
611 Herbert Jr EW, Shimanuki, H. 1977. Consumption and brood rearing by caged honeybees fed 612 pollen substitutes fortified with various sugars. Journal of Apicultural Research 17:27-31 $613 \quad$ https://doi.org/10.1080/00218839.1978.11099895

614 Imdorf A, Bogdanov S, Ibáñez Ochoa R, Calderone NW. 1999. Use of essential oils for the 615 control of Varroa jacobsoni Oud. in honey bee colonies. Apidologie 30:209-228. 616 https://doi.org/10.1051/apido:19990210

617 Kassambara A, Kosinski M. 2019. Drawing survival curves using 'ggplot2'. Version 0.4.4. 618 http://www.sthda.com/english/rpkgs/survminer/

619 Kuznetsova A, Brockhoff PB, Christensen RHB. 2019. Tests in linear mixed effects models. 620 https://github.com/runehaubo/lmerTestRhttps://github.com/runehaubo/lmerTestR

621 Lee KP, Simpson SJ, Wilson K. 2008. Dietary protein-quality influences melanization and 622 immune function in an insect. Functional Ecology 22(6):1052-1061 $623 \quad$ https://doi.org/10.1111/j.1365-2435.2008.01459.x 624 Lizama B. 2011. Levaduras asociadas a dos especies de abejas sin aguijón (Apidae: Meliponini) 625 y a tres especies de la flora nectarífera de Yucatán. MSc thesis. Centro de Investigación 626 Científica de Yucatán, Mérida, Yucatán, México. 77 p.

627 Lourenço AP, Zufelato MS, Bitondi M, Simões ZLP. 2005. Molecular characterization of a 628 cDNA encoding prophenoloxidase and its expression in Apis mellifera. Insect 629 Biochemistry and Molecular Biology 35(6):541-552 630 https://doi.org/10.1016/j.ibmb.2005.01.013 631 Maistrello L, Lodesani M, Costa C, Leonardi F, Caldon M, Mutinelli F, Granato A. 2008. 632 Screening of natural compounds for the control of nosema disease in honey bees (Apis mellifera). Apidologie 39:436-445 https://doi.org/10.1051/apido:2008022 
634 Martínez-Natarén DA, Parra-Tabla V, Ferrer-Ortega M.M, Calvo-Irabién LM. 2014. Genetic 635 diversity and genetic structure in wild populations of Mexican oregano (Lippia graveolens 636 H.B.K.) and its relationship with the chemical composition of the essential oil. Plant 637 Systematic and Evolution 300:535-547 https://doi.org/10.1007/s00606-013-0902-y 638 Merkx-Jacques M, Bede JC. 2005. Influence of diet on the larval beet armyworm, Spodoptera 639 exigua, glucose oxidase activity. Journal of Insect Science 5:48. 640 https://doi.org/10.1093/jis/5.1.48

641 Nazaaro F, Fratianni F, Coppola R, De Feo V. 2017. Essential oils and antifungal activity. Pharmaceuticals 10(4):86 https://doi.org/10.3390/ph10040086

Negri P, Villalobos E, Szawarski N, Damiani N, Gende L, Garrido M, Maggi M, Quintana, S, 644 Lamattina L, Eguaras M. 2019. Towards precision nutrition: a novel concept linking 645 phytochemicals, immune response and honey bee health. Insects 10:401 https://doi.org/10.3390/insects 10110401

647 Ohashi K, Natori S, Kubo T. 1999. Expression of amylase and glucose oxidase in the 648 hypopharyngeal gland with an age-dependent role change of the worker honey bee (Apis mellifera L.). European Journal of Biochemistry 265(1):127-133. protein to carbohydrate ratio for survival and ovarian activation of caged honeybees (Apis mellifera scutellata). Apidologie 41:62-67 https://doi.org/10.1051/apido/2009055

654 R Core Team. 2018. R: A language and environment for statistical computing. R Foundation for 655 Statistical Computing https://www.R-project.org/. 
656 Ramsey S, Ochoa R, Bauchan G, Gulbronson C, Mowery JD, Cohen A, Lim D, Joklik J, Cicero

657 JM, Ellis JD, Hawthorne D, vanEngelsdorp D. 2019. Varroa destructor feeds primarily on 658 honey bee fat body tissue and not hemolymph. PNAS 116(5): 1792-1801.

659 https://doi.org/10.1073/pnas.1818371116

660 Rosa CA, Lachance MA, Silva JOC, Teixeira ACP, Marini MM, Antonini Y, Martins RP. 2003.

661 Yeast communities associated with stingless bees. FEMS Yeast Research 4(3): 271-275

662 https://doi.org/10.1016/S1567-1356(03)00173-9

663 Schmid MR, Brockmann A, Pirk CW, Stanley DW, Tautz J. 2008. Adult honey bees (Apis 664 mellifera L.) abandon hemocytic, but not phenoloxidase-based immunity. Journal of Insect Physiology 54(2):439-444 https://doi.org/10.1016/j.jinsphys.2007.11.002

666

667

668

669

670

671

672

673

674

675

676

677

678

Schmittgen TD, Livak KJ. 2008. Analyzing real-time PCR data by the comparative CT method. Nature Protocols 3:1101-1108. https://doi.org/10.1038/nprot.2008.73

Shad DJ, Vasishth S, Hohenstein S, Kliegl R. 2020. How to capitalize on a priori contrasts in linear (mixed) models: A tutorial. Journal of Memory and Language 110:104038 https://doi.org/10.1016/j.jml.2019.104038

Sihag RC, Gupta M. 2011. Development of an artificial pollen substitute/supplement diet to help tide the colonies of honey bee (Apis mellifera L.) over the dearth season. Journal of Apicultural Science 55(2):15-29.

Smodiš Škerl MI, Gregorc A. 2014. A preliminary laboratory study on the longevity of $A . m$. carnica honey bees after feeding with candies containing HMF. Journal of Apicultural Research 53:422-423 http://dx.doi.org/10.3896/IBRA.1.53.4.07

Srygley RB, Lorch PD, Simpson SJ, Sword GA. 2009. Immediate protein dietary effects on movement and the generalised immunocompetence of migrating Mormon crickets Anabrus 
simplex (Orthoptera: Tettigoniidae). Ecological Entomology 34:663-668

680 https://doi.org/10.1111/j.1365-2311.2009.01117.x

681 Standifer LN, McCaughey WF, Todd FE, Kemmerer AR. 1960. Relative availability of various 682 proteins to the honey bee. Annals of the Entomological Society of America 53:618-625 https://doi.org/10.1093/aesa/53.5.618

684 685

686

687

688

689

690

691

692

693

694

695

696

697

698

699

700

Takenaka T, Ito H, Yatsunami K, Echigo T. 1990. Changes of glucose oxidase activity and amount of gluconic acid formation in the hypopharyngeal glands during the lifespan of honey bee workers (Apis mellifera L.). Agricultural and Biological Chemistry 54(8):21332134 https://doi.org/10.1080/00021369.1990.10870255

Therneau TM. 2019. Survival Analysis. Version 2. 44-1.1. https://github.com/therneau/survival Toth AL, Kantarovich S, Meisel AF, Robinson GE. 2005. Nutritional status influences socially regulated foraging ontogeny in honey bees. The Journal of Experimental Biology 208:4641-4649 https://doi.org/10.1242/jeb.01956

Tsuruda JM, Amdam GV, Page RE. 2008. Sensory response system of social behavior tied to female reproductive traits. PLOS One 3(10):e3397 https://doi.org/10.1371/journal.pone.0003397

van der Steen J. 2007. Effect of a home-made pollen substitute on honey bee colony development. Journal of Apicultural Research 46(2):114-119 https://doi.org/10.1080/00218839.2007.11101377

Williams GR, Alaux C, Costa C, Csaki T, Doublet V, Eisenhardt D, Fries I, Kuhn R, McMahon DP, Medrzycki P, Murray TE, Natsopoulou ME, Neumann P, Oliver R, Paxton RJ, Pernal SF, Shutler D, Tanner G, van der Steen JJM, Brodschneider R. 2013. Standard methods for 
701 maintaining adult Apis mellifera in cages under in vitro laboratory conditions. Journal of 702 Apicultural Research 52(1):1-36 https://doi.org/10.3896/IBRA.1.52.1.04

703 Wilson-Rich N, Dres ST, Starks PT. 2008. The ontogeny of immunity: development of innate 704 immune strength in the honey bee (Apis mellifera). Journal of Insect Physiology 54(10-

705

706

Yang X, Cox-Foster DL. 2005. Impact of an ectoparasite on the immunity and pathology of an

707 invertebrate: evidence for host immunosuppression and viral amplification. Proc.

708 Proceedings of the National Academy of Sciences 102(21):7470-7475

709 https://doi.org/10.1073/pnas.0501860102

710 


\section{Table $\mathbf{1}$ (on next page)}

Chemical composition of the essential oil of Mexican oregano Lippia graveolens.

Chemical composition and concentration $(\mathrm{mg} / \mathrm{ml}$ ) of three types of essential oils (EO) identified in the Mexican oregano (Lippia graveolens). The table shows the main compounds of each type of oil produced by this species highlighting (bold) the dominant compounds for each type: carvacrol, thymol, and sesquiterpenes. 
1

\begin{tabular}{|l|c|c|c|}
\hline Compounds & \multicolumn{3}{|c|}{ Essential oil types } \\
\hline p-Cymene & Carvacrol & Thymol & Sesquiterpenes \\
\hline Eucalyptol & 10.20 & 6.25 & 1.53 \\
\hline y-Terpinene & 0.66 & 1.37 & 1.88 \\
\hline Thymol & 2.17 & 0.74 & 0.37 \\
\hline Carvacrol & 2.39 & $\mathbf{2 2 . 0 7}$ & 0.08 \\
\hline$\beta$-Caryophyllene & $\mathbf{3 8 . 8 9}$ & $2 \times 10^{-7}$ & 0.13 \\
\hline$\alpha$-Humulene & 2.79 & 6.26 & $\mathbf{1 4 . 6 9}$ \\
\hline Caryophyllene oxide & 1.32 & 3.16 & $\mathbf{6 . 5 5}$ \\
\hline
\end{tabular}

2 


\section{Figure 1}

Experimental design.

Two brood frames were removed from 20 colonies of Africanized worker bees Apis mellifera and incubated under controlled laboratory conditions. The newly emerged bees were placed in hoarding cages and fed one of nine artificial diets for 9-12 days. Next, six response variables indicative of the bees' health and immune function were measured in fed bees (illustration and photograph credit: Azucena Canto and Luis Medina-Medina).

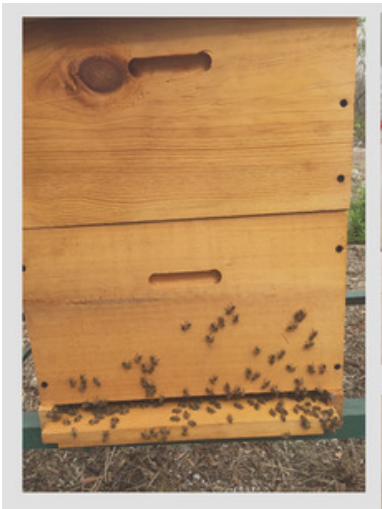

20

Apis mellifera colonies

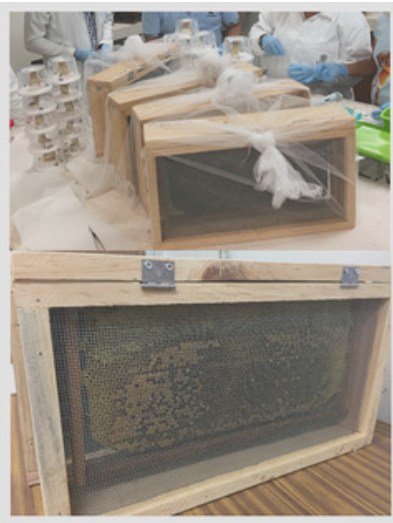

$1-2$

brood frames / colony

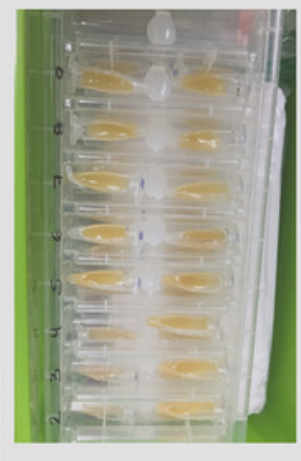

9

type of diets

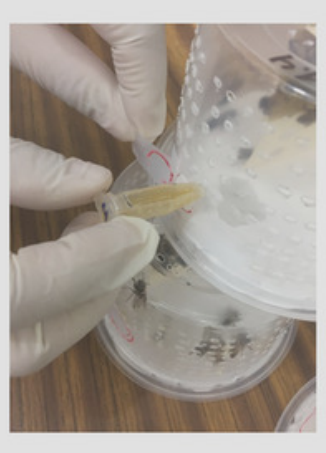

25-30 bees / cage

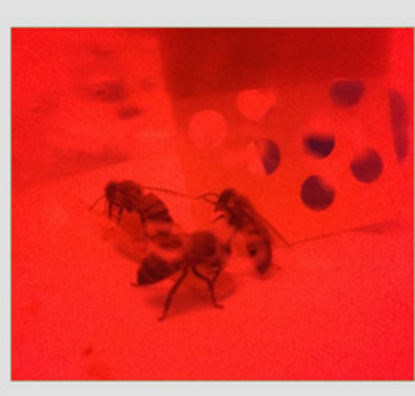

9 cages / type of diet
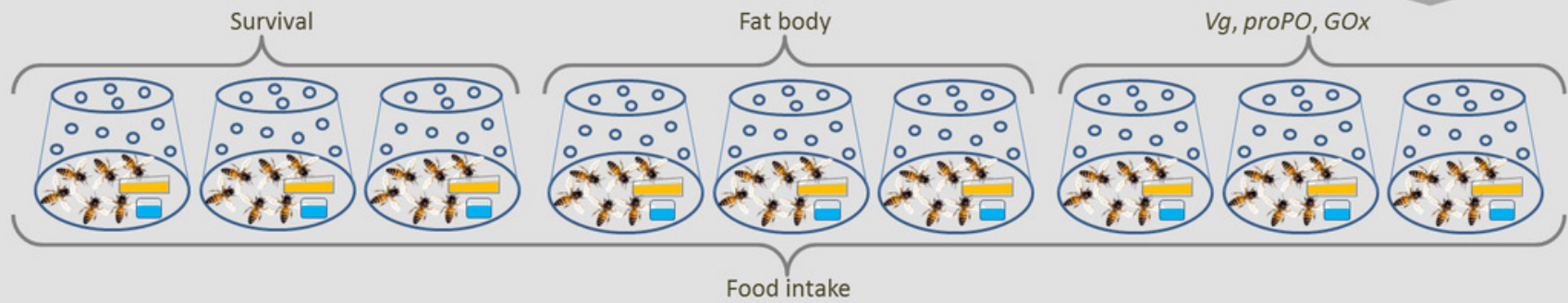


\section{Figure 2}

Survival probability

Survival curves for Africanized worker bees Apis mellifera fed one of nine artificial diets for 12 days. Enriched diets contained one of five bee-associated yeasts or one of three types of essential oil: (A) Starmerella bombicola; (B) Starmerella etchellsii; (C) Starmerella bombicola 2; (D) Zygosaccharomyces mellis; (E) Saccharomyces cerevisiae; (F) carvacrol; (G) thymol; (H) sesquiterpenes. Each plot compares the control (base) to each treatment diet. Dashed black lines indicate median survival time. P-values are derived from the Log-Rank test to compare differences between the control diet and each treatment group. Data points depict the mean value \pm SE of survival probability. 

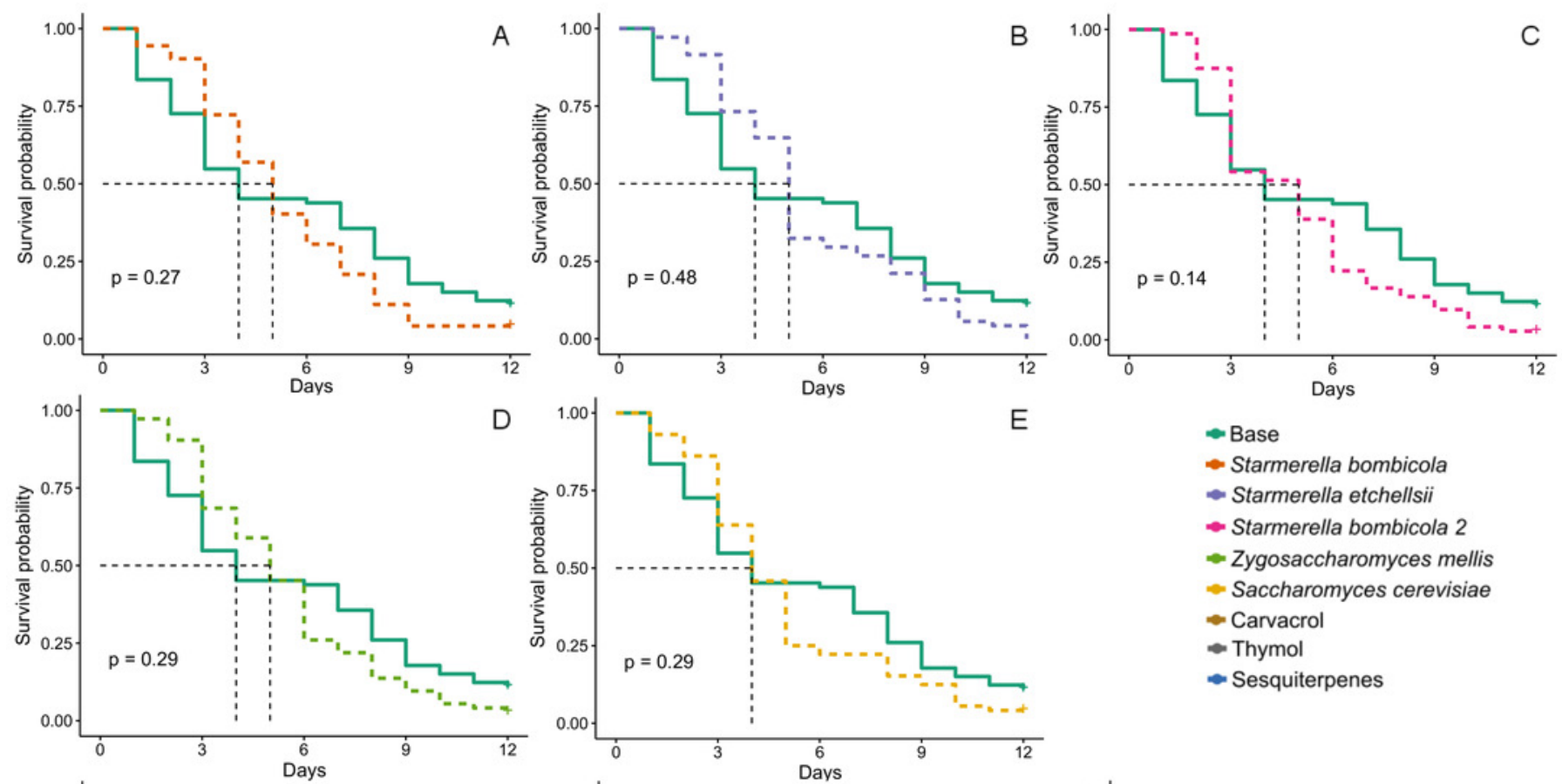

E
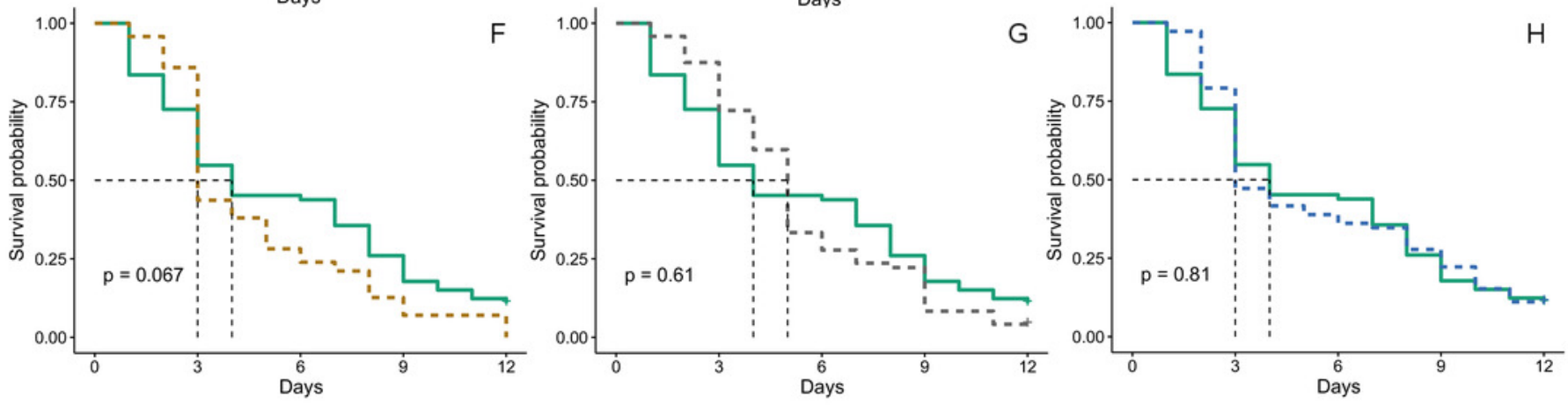


\section{Figure 3}

Food intake.

Food intake for Africanized worker bees Apis mellifera fed one of nine artificial diets for nine days. Enriched diets contained one of five bee-associated yeasts or one of three types of essential oil: (A) Starmerella bombicola; (B) Starmerella etchellsii; (C) Starmerella bombicola 2; (D) Zygosaccharomyces mellis; (E) Saccharomyces cerevisiae; (F) carvacrol; (G) thymol; (H) sesquiterpenes. Each plot compares the control (Base) to each treatment diet. Data points depict the mean $\pm \mathrm{SE}$ of food intake ( $\mathrm{mg} / \mathrm{bee} /$ day).
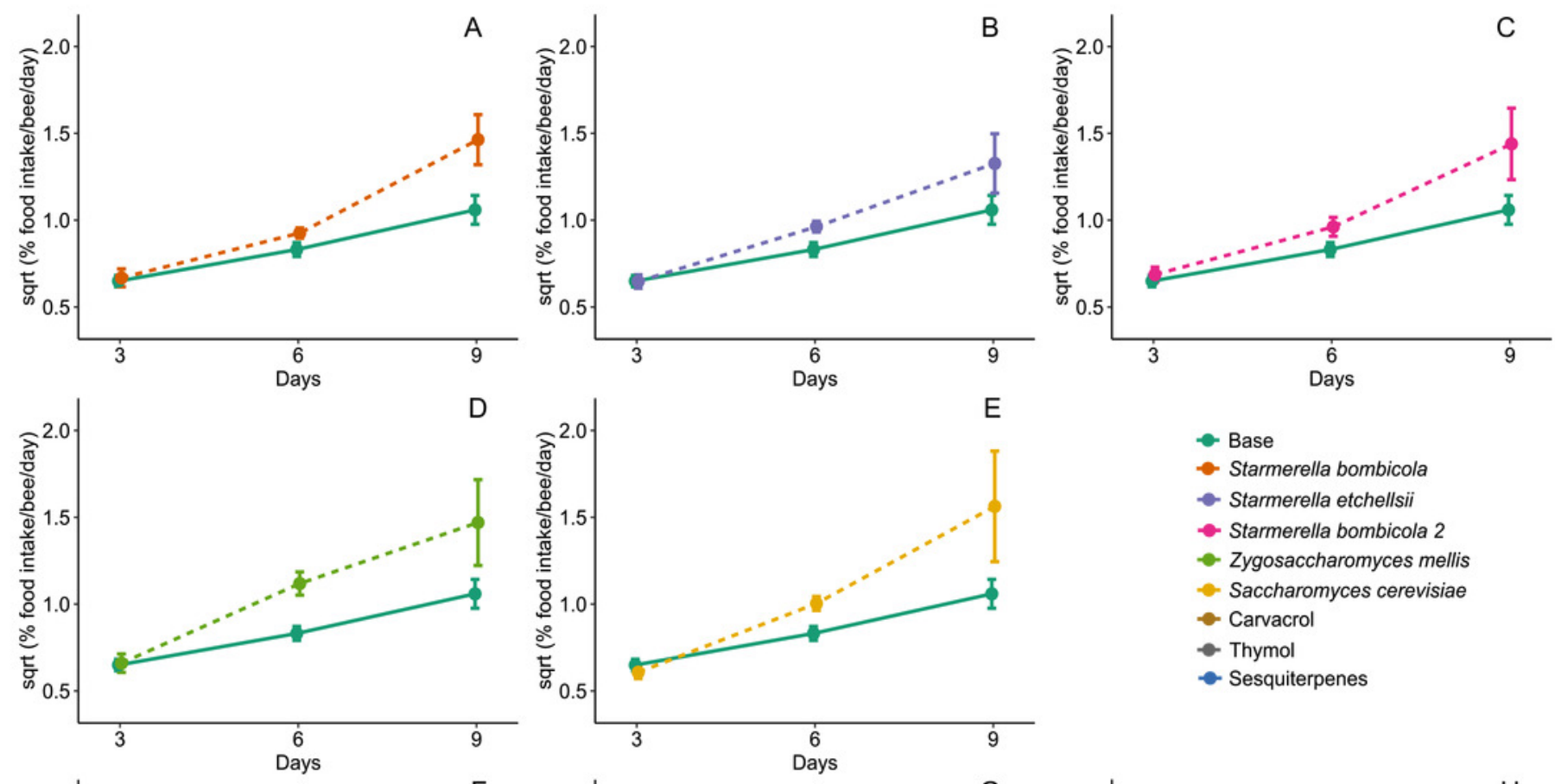

- Starmerella bombicola

- Starmerella bombicola 2

- Zygosaccharomyces mellis

- Saccharomyces cerevisiae

- Carvacrol

- Thymol

- Sesquiterpenes
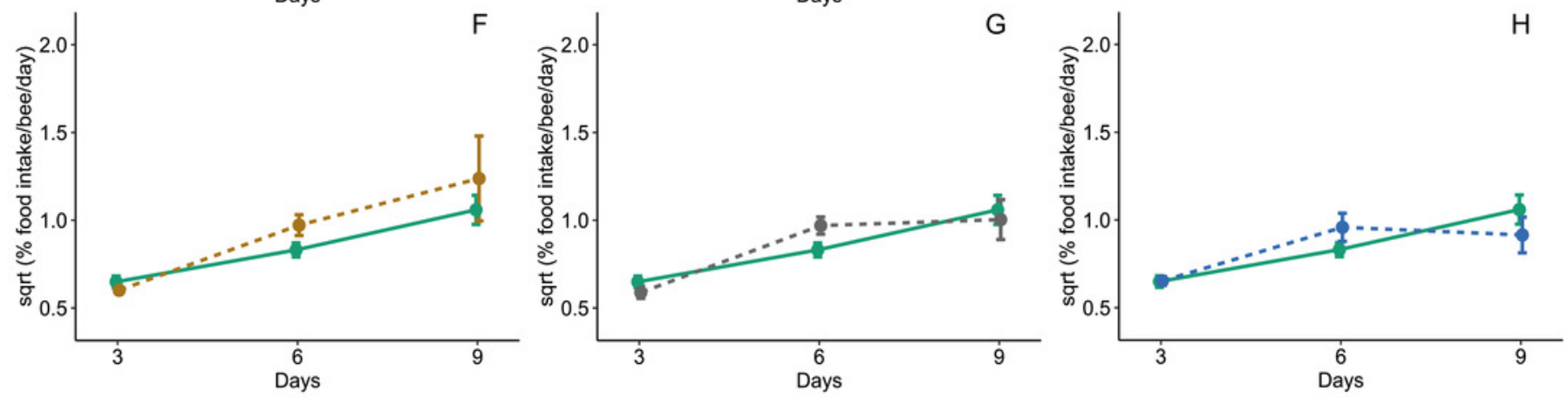


\section{Figure 4}

Fat body accumulation.

Percent of fat body accumulation for Africanized worker bees Apis mellifera fed nine artificial diets for nine days. Enriched diets contained one of five bee-associated yeasts or one of three types of essential oil: (A) Starmerella bombicola; (B) Starmerella etchellsii; (C)

Starmerella bombicola 2; (D) Zygosaccharomyces mellis; (E) Saccharomyces cerevisiae; (F) carvacrol; $(\mathrm{G})$ thymol; $(\mathrm{H})$ sesquiterpenes. Each plot compares the control (Base) to each treatment diet. Data points depict the mean \pm SE of fat body accumulation in bee abdomens (\%). 

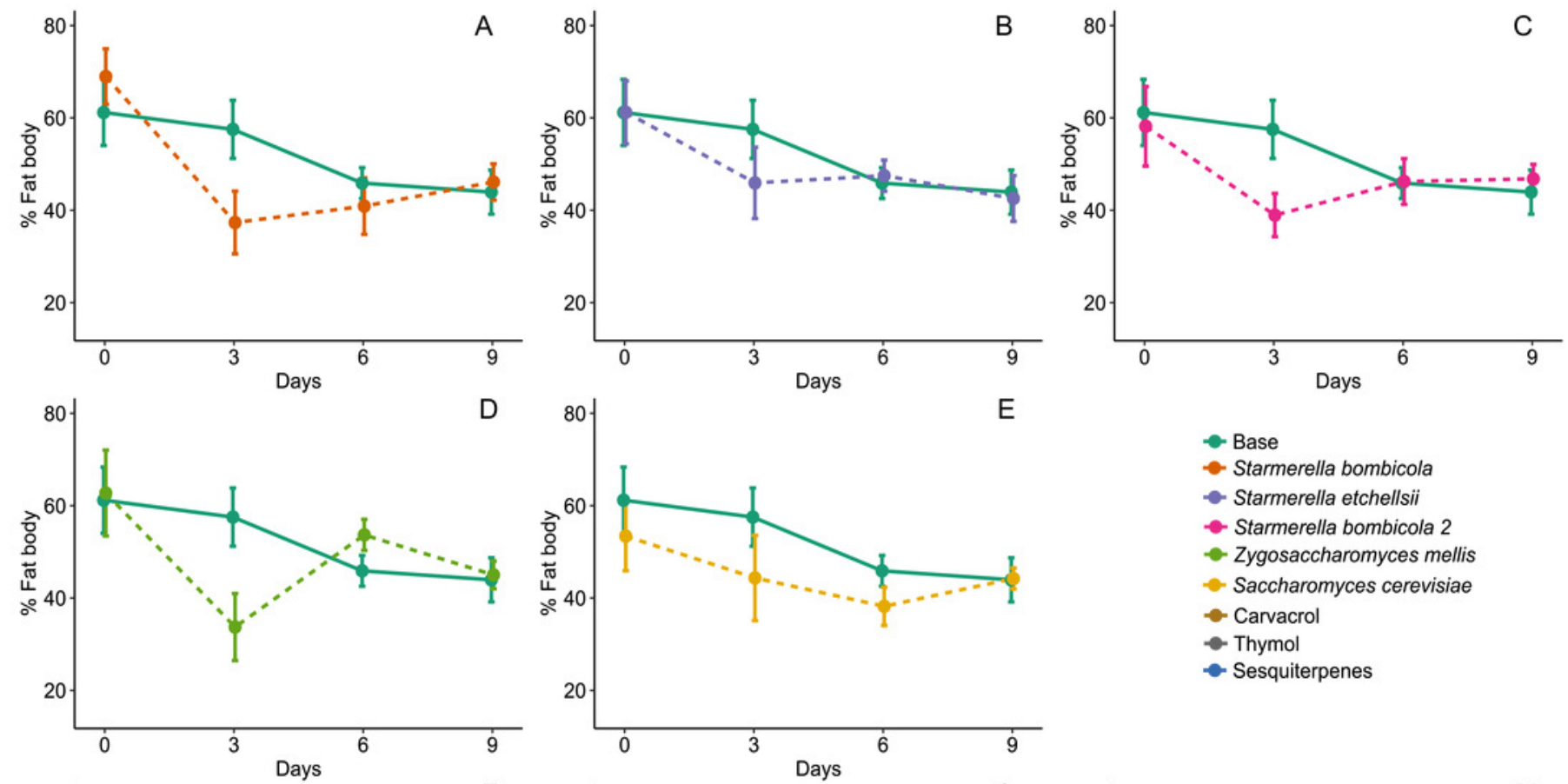

- Base

- Starmerella bombicola

- Starmerella etchellsii

- Starmerella bombicola 2

- Zygosaccharomyces mellis

- Saccharomyces cerevisiae

- Carvacrol

- Thymol

- Sesquiterpenes
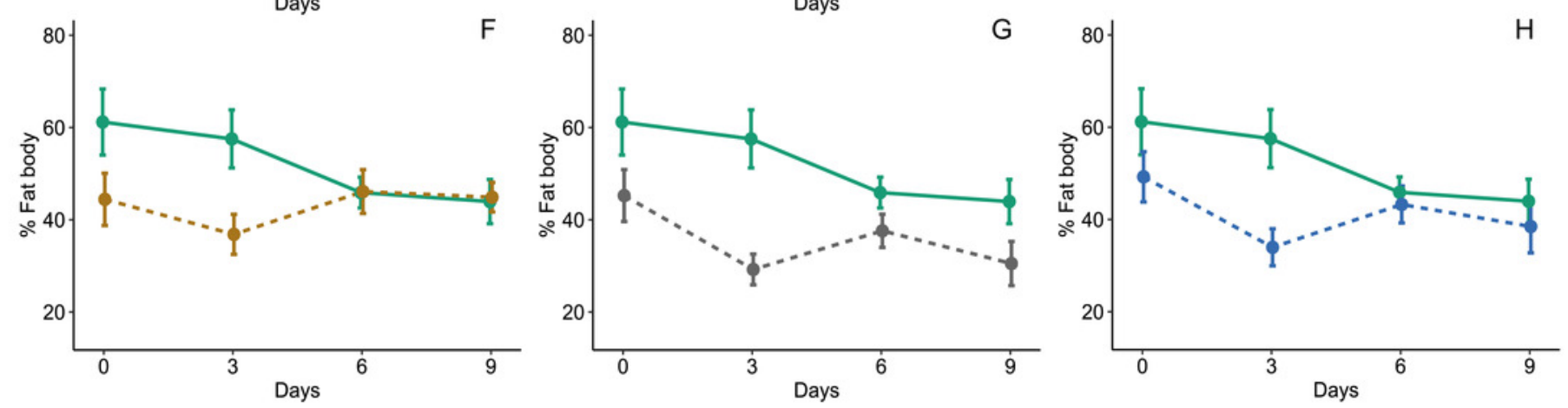
Figure 5

Expression of $V g$ gene by RT-qPCR.

Relative expression levels (REL) of the $V g$ gene in Africanized worker bees Apis mellifera fed nine artificial diets for nine days. Enriched diets contained one of five bee-associated yeasts or one of three types of essential oil: (A) Starmerella bombicola; (B) Starmerella etchellsii; (C) Starmerella bombicola 2; (D) Zygosaccharomyces mellis; (E) Saccharomyces cerevisiae; (F) carvacrol; $(\mathrm{G})$ thymol; $(\mathrm{H})$ sesquiterpenes. Each plot compares the control (Base) to each treatment diet. Data points depict the mean \pm SE of $V g$ REL.
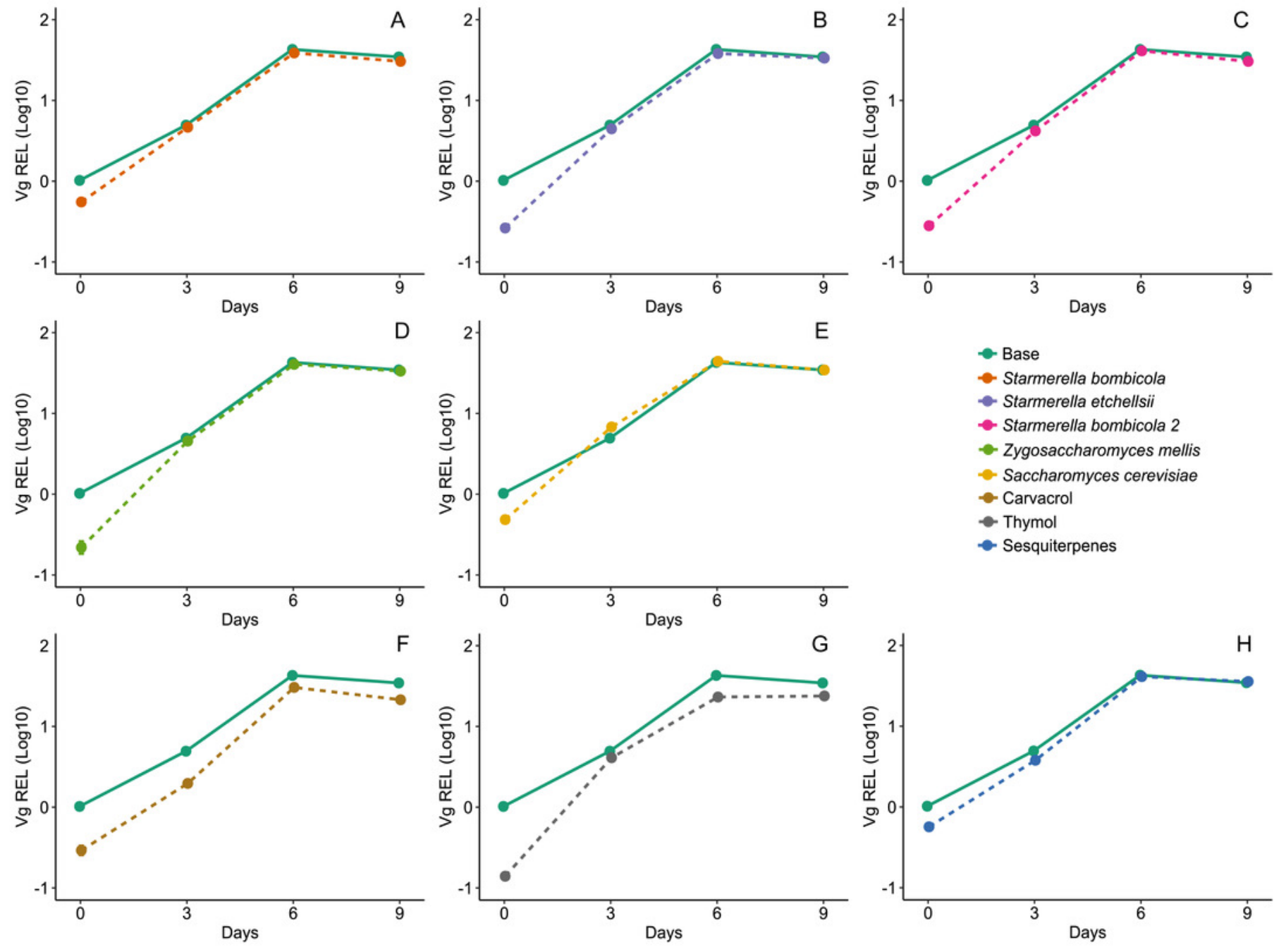


\section{Figure 6}

Expression of proPO gene by RT-qPCR.

Relative expression levels (REL) of proPO gene in Africanized worker bees, Apis mellifera, fed nine artificial diets for nine days. Enriched diets contained one of five bee-associated yeasts or one of three types of essential oil: (A) Starmerella bombicola; (B) Starmerella etchellsii; (C) Starmerella bombicola 2; (D) Zygosaccharomyces mellis; (E) Saccharomyces cerevisiae; (F) carvacrol; (G) thymol; $(H)$ sesquiterpenes. Each plot compares the control (Base) to each treatment diet. Data points depict the mean \pm SE of proPO REL.
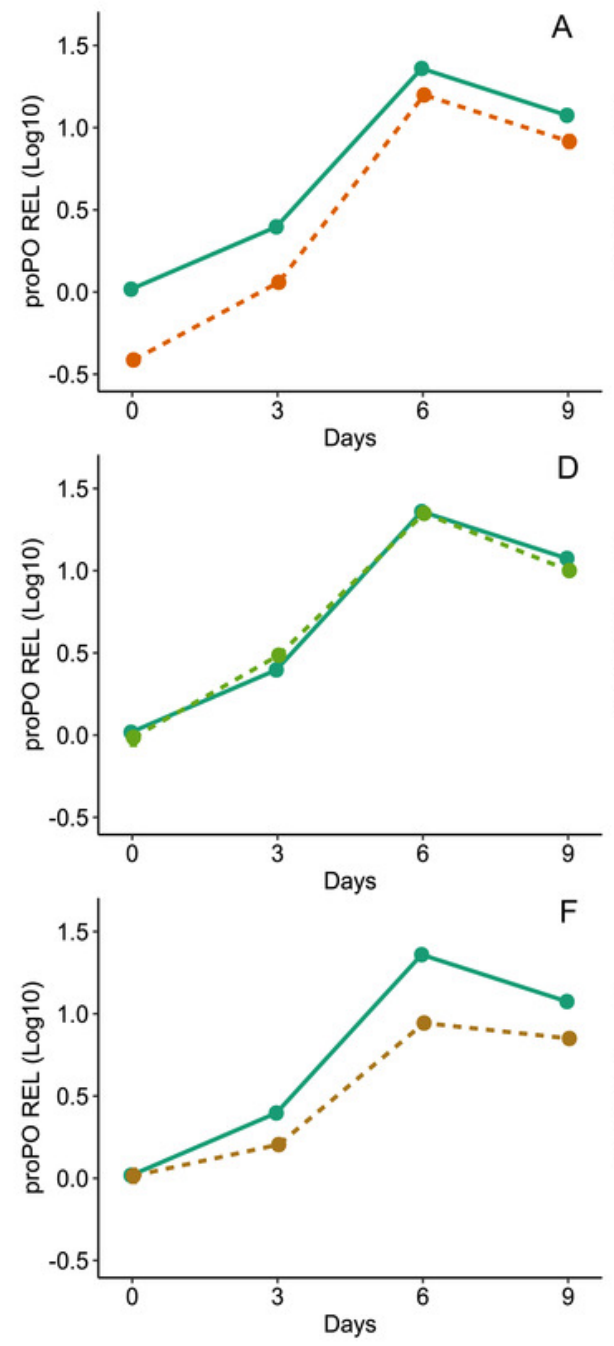
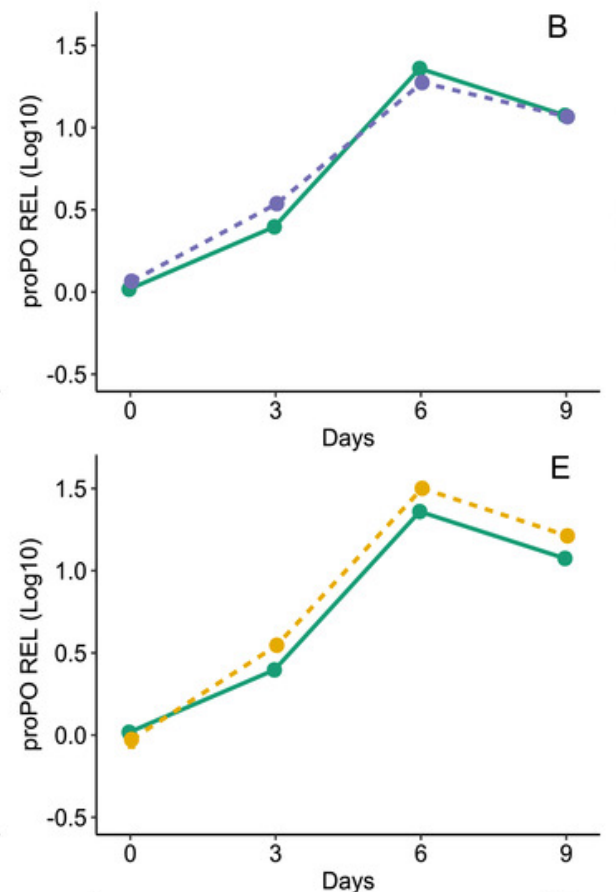

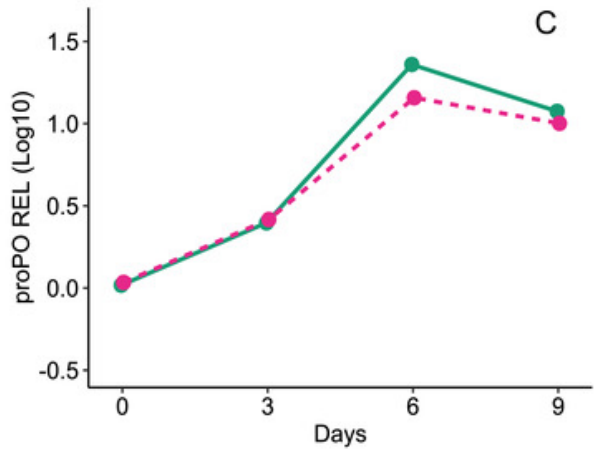

- Base

- Starmerella bombicola

- Starmerella etchellsii

- Starmerella bombicola 2

- Zygosaccharomyces mellis

- Saccharomyces cerevisiae

- Carvacrol

- Thymol

- Sesquiterpenes

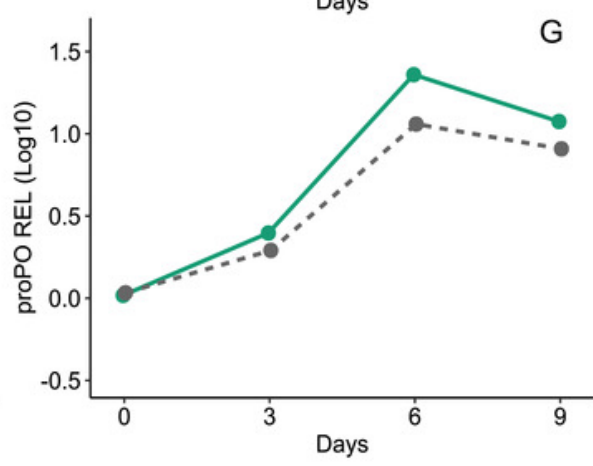

$\mathrm{H}$

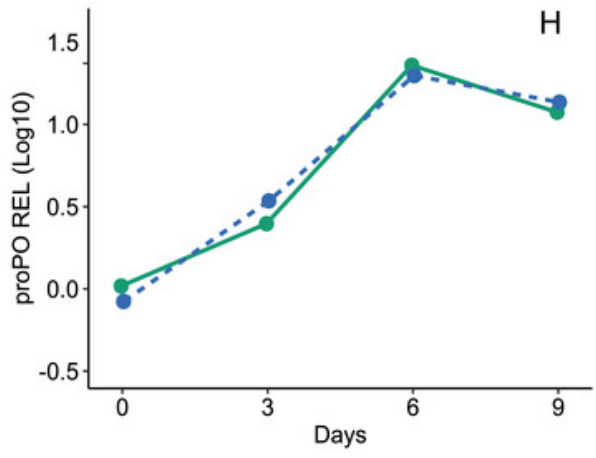


Figure 7

Expression of GOx gene by RT-qPCR.

Relative expression levels (REL) of GOx gene of Africanized worker bees, Apis mellifera, fed nine artificial diets for nine days. Enriched diets contained one of five bee-associated yeasts or one of three types of essential oil: (A) Starmerella bombicola; (B) Starmerella etchellsii; (C) Starmerella bombicola 2; (D) Zygosaccharomyces mellis; (E) Saccharomyces cerevisiae; (F) carvacrol; (G) thymol; (H) sesquiterpenes. Each plot compares the control (Base) to each treatment diet. Data points depict the mean \pm SE of GOx REL.
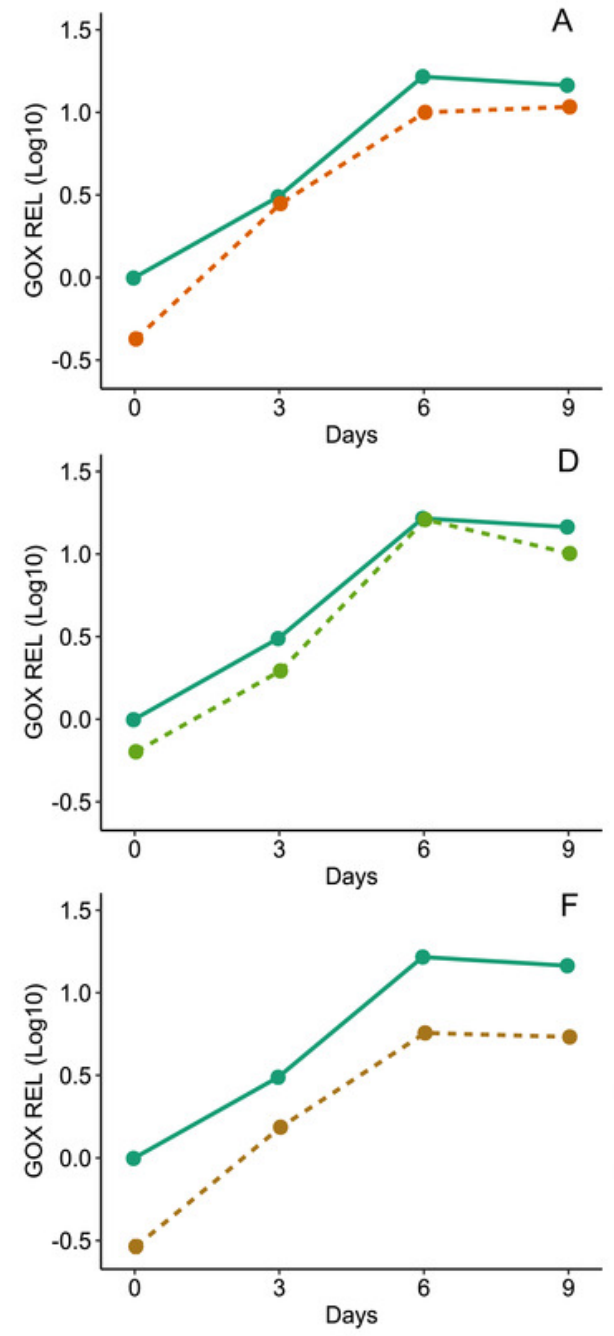
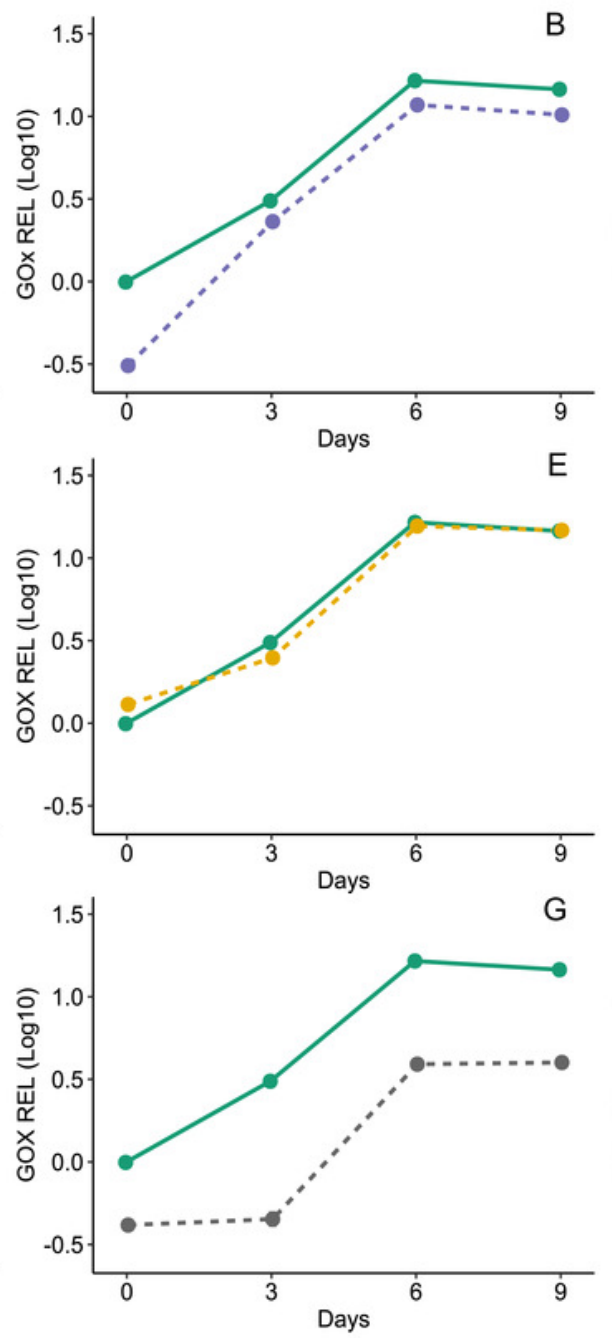
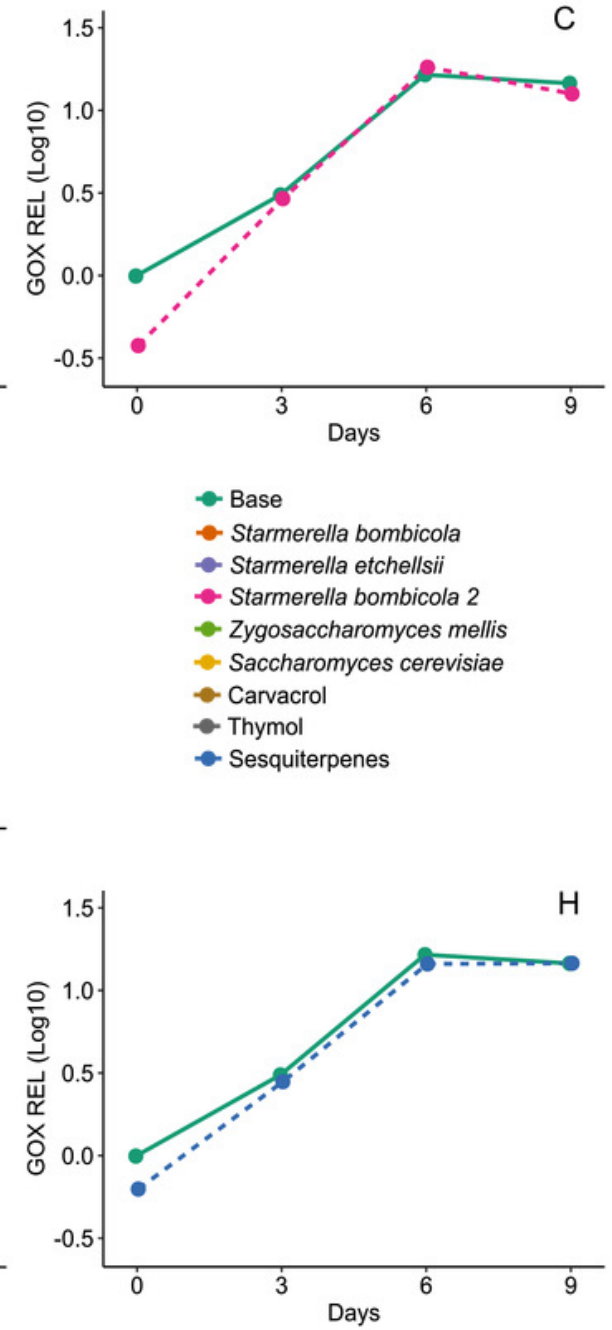